NBER WORKING PAPER SERIES

\title{
THE GREEN BOOKS AND THE GEOGRAPHY OF SEGREGATION IN PUBLIC ACCOMMODATIONS
}

\author{
Lisa D. Cook \\ Maggie E.C. Jones \\ David Rosé \\ Trevon D. Logan \\ Working Paper 26819 \\ http://www.nber.org/papers/w26819 \\ NATIONAL BUREAU OF ECONOMIC RESEARCH \\ 1050 Massachusetts Avenue \\ Cambridge, MA 02138 \\ March 2020
}

\begin{abstract}
We would like to thank Rob Clark, Matt Gregg, Taylor Jaworski, Ian Keay, and Anji Redish for valuable comments. We also thank seminar participants at the University of Missouri, Northwestern University, Queen's University, the University of Victoria, York University, and conference participants at the 2019 NBER Summer Institute (DAE), 2019 CEA meetings, 2019 SSHA meetings, and 2019 SEA meetings for useful feedback. This work would not have been possible without the help of our dedicated team of research assistants: Ashley Brewster, Maddy Conkle, Jack Csokmay, Vi Dinh, Mark Drodz, Matthew Edwards, Alisa Feng, Fahim Hossain, Daniel Lake, Ryan Scott, Daniel Missell, Abby Nenna, Yamini Panagari, Ethan Pointer, Jessica Shakesprere, Morgan Thompson, Julia Uhler, and Lingxuan Yang. We are grateful for the help of Peggy Ann Brown and Kevin Morrow at the Library of Congress. All errors are our own. The views expressed herein are those of the authors and do not necessarily reflect the views of the National Bureau of Economic Research.
\end{abstract}

NBER working papers are circulated for discussion and comment purposes. They have not been peer-reviewed or been subject to the review by the NBER Board of Directors that accompanies official NBER publications.

(C) 2020 by Lisa D. Cook, Maggie E.C. Jones, David Rosé, and Trevon D. Logan. All rights reserved. Short sections of text, not to exceed two paragraphs, may be quoted without explicit permission provided that full credit, including $\odot$ notice, is given to the source. 
The Green Books and the Geography of Segregation in Public Accommodations

Lisa D. Cook, Maggie E.C. Jones, David Rosé, and Trevon D. Logan

NBER Working Paper No. 26819

March 2020

JEL No. J15,L83,N32,N82,N92

\begin{abstract}
Jim Crow segregated African Americans and whites by law and practice. The causes and implications of the associated de jure and de facto residential segregation have received substantial attention from scholars, but there has been little empirical research on racial discrimination in public accommodations during this time period. We digitize the Negro Motorist Green Books, important historical travel guides aimed at helping African Americans navigate segregation in the pre-Civil Rights Act United States. We create a novel panel dataset that contains precise geocoded locations of over 4,000 unique businesses that provided nondiscriminatory service to African American patrons between 1938 and 1966. Our analysis reveals several new facts about discrimination in public accommodations that contribute to the broader literature on racial segregation. First, the largest number of Green Book establishments were found in the Northeast, while the lowest number were found in the West. The Midwest had the highest number of Green Book establishments per black resident and the South had the lowest. Second, we combine our Green Book estimates with newly digitized county-level estimates of hotels to generate the share of non-discriminatory formal accommodations. Again, the Northeast had the highest share of non-discriminatory accommodations, with the South following closely behind. Third, for Green Book establishments located in cities for which the Home Owner's Loan Corporation (HOLC) drew residential security maps, the vast majority (nearly 70 percent) are located in the lowest-grade, redlined neighborhoods. Finally, Green Book presence tends to correlate positively with measures of material well-being and economic activity.
\end{abstract}

Lisa D. Cook

Department of Economics

Michigan State University

486 W. Circle Drive

East Lansing, MI 48824

and NBER

lisacook@msu.edu

Maggie E.C. Jones

Department of Economics

Business and Economics Building

University of Victoria

Victoria, British Columbia V8P 5C2

Canada

maggie.ec.jones@gmail.com
David Rosé

Department of Economics

Lazaridis School of Business and Economics

Wilfrid Laurier University

Waterloo, Ontario N2L 3C7

Canada

darose@wlu.ca

Trevon D. Logan

The Ohio State University

410 Arps Hall

1945 N. High Street

Columbus, $\mathrm{OH} 43210$

and NBER

logan.155@osu.edu 
"Do you remember any good stopping places

in Arizona or western Texas?

Anything in Phoenix or El Paso?

And what is the best route from here to the coast?

I have never driven it, you know."

- Arna Bontemps, quoted by Wilkerson (2010)

Jim Crow segregated African Americans and whites by law and practice. The causes and implications of the associated de jure and de facto residential segregation have received substantial attention from scholars. The consensus is that residential segregation exacerbated racial disparities in income, employment, education, political influence, and homeownership (Cutler and Glaeser, 1997; Card and Rothstein, 2007; Ananat and Washington, 2009; Ananat, 2011; Aaronson, Hartley, and Mazumder, 2018). Relatively less attention has been paid to understanding segregation's role in access to public accommodations and business ownership..$^{1}$ This is not due to a lack of interest or importance-after all, the entire Jim Crow era is characterized by the denial of services to African American consumers-rather, the absence of reliable data on the location and quantity of non-discriminatory businesses has hampered researchers' ability to investigate this topic.

This paper makes use of an important historical tool created to assist African Americans in navigating segregation. From 1936 to 1960, Harlem postal worker Victor Green published travel guides for African American motorists..$^{2}$ Colloquially known as the Green Books, these directories listed hotels, businesses, restaurants, and other services that were friendly towards African American clientele during a time when travel could be uncomfortable, at best, and dangerous, at worst. We use the Green Books to uncover regional, county-, and city-level patterns of discrimination in access to public accommodations. By digitizing and geocoding the exact location of all establishments listed in the Green Books between 1938

\footnotetext{
${ }^{1}$ An important exception is Gil and Marion (2019) who exploit a ban against segregation in Washington, D.C. in 1953 to test whether segregation in cinemas was due to taste-based discrimination among firms (cinema owners) or consumers, or both parties. Whereas, they focus on a narrow industry (cinemas located in 26 cities), we present evidence on the geographic and temporal extent of access to public accommodations across industries for counties throughout the continental United States. Another exception is Roback (1986)'s study of segregated streetcars. Roback's central thesis differs from our paper, as she questions whether the development of the Jim Crow system was motivated by political factors or changed attitudes towards blacks. In contrast to studying how segregation affected the demand for services among African Americans, Cook (2012b) examines the strategies black inventors developed to cope with consumer-side discrimination, with a particular emphasis on the strategies implemented by Garret A. Morgan, inventor of both the gas mask and traffic light.

2 Taylor (2020) documents that Victor Green worked on the Green Books up until the time of his death in 1960. His wife, Alma, ran the publication for the following two years. The final two issues, the 1963-64 and 1966-67 editions, were published by Langley Waller, a former writer for the New York Amsterdam News-Harlem's newspaper.
} 
and 1964, we provide a unique lens into the geography of racial discrimination in public accommodations during the last years of legal Jim Crow in the United States.

Our analysis reveals several new facts related to the history of accessibility of public accommodations to African Americans. First, access to non-discriminatory establishments was not uniform across the United States. The largest number of Green Book establishments were found in the Northeast, while the West had the fewest number of Green Book establishments. The Midwest had the largest number of establishments per black resident, while the South had the least.

Second, since areas with a large number of Green Book establishments may be areas that have more establishments in general, we also digitize the retail section of the 1935 and 1948 Census of Business to obtain county-level values of the total number of hotels and motels. Combining formal accommodation counts from the Green Books with the Census of Business counts allows us to compute the share of non-discriminatory hotels and motels by county. Using this measure, we find again, that the Northeast had the highest share of nondiscriminatory accommodations, with the South lagging slightly behind. The finding that the South was relatively close to the Northeast in terms of the share of non-discriminatory accommodations is not dissimilar to patterns of residential segregation found during the early twentieth century in national measures of segregation (Logan and Parman, 2017).

Next, we investigate how the location of Green Book establishments within cities relates to the practice of redlining, wherein the Home Owner's Loan Corporation (HOLC) drew residential security maps of 239 American cities in the 1930s to caution lenders against lending to patrons in high-risk neighborhoods (Aaronson et al., 2018). Nearly 50 percent of the Green Book establishments are located in cities for which digitized HOLC security maps are available, the vast majority of which (69 percent) were located in the lowest-grade, redlined neighborhoods. The next largest group of Green Book establishments were located in no-grade (likely business district) areas. While we hesitate to draw strong conclusions about establishments in D-grade versus no-grade neighborhoods, we suggest that this may reflect racial differences in business ownership.

Finally, we estimate a series of elasticities of the number of Green Book establishments with respect to a set of covariates to understand how Green Book presence relates to economic activity, material well-being, and existing measures of segregation and discrimination. We find that the presence of Green Book establishments correlates positively with the prevalence of electricity, radios, refrigerators, manufacturing activity, and war contracts; however, conditioning on the counts from the Census of Business reveals that these elasticities are primarily explained by the fact that places with more economic activity also have more accommodations. 
We also find that Green Book prevalence is positively correlated with the number of Confederate symbols in a county, which would suggest that more Green Book establishments may proxy for racial animus; however, they are not associated with another measure of racial animosity-black lynchings-once we account for the prevalence of all accommodations from the Census of Business. This result is at odds with the existing literature that has found areas with more historical lynchings to have more Confederate streets (Williams, 2019).

At the state-level, we use the legislative changes made to discrimination and antidiscrimination laws across the United States by 1950 to understand how Green Book presence is related to legal segregation in the U.S. We digitize nearly 2000 instances, originally compiled by Murray (1950), that describe either the strengthening or weakening of discriminatory legislation within a state. Perhaps unsurprisingly, we find that discriminatory laws are positively correlated with the presence of informal accommodation listings in the Green Books, while anti-discrimination laws correlate positively with all industry types.

The remainder of the paper is outlined as follows. Section 2 provides a background of the Green Books and describes our digitization process, including a discussion of the procedure by which we generated a panel of establishments over time, as well as the method we used to geocode establishment locations. Section 3 presents our findings on regional and city trends. We discuss selection into the Green Books in Section 4 and the correlates of Green Book establishments in Section 5 . Section 6 provides a brief summary of our findings and concludes.

\section{Assembling the Green Book Data}

\subsection{A Brief History of the Green Books}

The Negro Motorist Green Books (henceforth, Green Books) were a series of travel guides published during the Jim Crow era, that were created by Victor Hugo Green, an African American postal employee from Harlem, New York City. Green's objective was to provide information on businesses that African American motorists could frequent without jeopardizing their safety. Although the Jim Crow laws that segregated the Southern US did not extend to the North and West, many communities in these areas practiced segregation de facto ${ }^{3}$ The Green Books provided a directory of safe places that African American tourists could rely upon while traveling.

The first Green Book was published in 1936 as a ten-page pamphlet containing New York

\footnotetext{
${ }^{3}$ By 1960, over 10,000 cities across the North, Midwest, and West had become established "sundown towns" - localities where African Americans were threatened with violence after nightfall (Loewen, 2009).
} 
City establishments that served African Americans. $4^{4}$ The idea behind the Green Books was borne from Green's own experience with racial discrimination while traveling with his wife, Alma, in 1936 (Brown, 2017). During this time period, African American motorists were often advised to drive below the speed limit and even under the cover of night to avoid confrontations with police (Sugrue, 2010). At a time when lynchings were still occurring in the southern US and "sundown towns" barred African Americans from entering after dark, the threat of racial discrimination on the road was not only uncomfortable for African American travelers, but could also result in potentially life-threatening encounters. 5

Green's original publication listing non-discriminatory establishments in New York City in 1936 was so successful that coverage was expanded across the Northeast in the following year and nationally the year after. While the original intention of the Green Book was to help African American motorists undertake their journeys safely, by providing listings of gas stations, hotels, motels, and tourist homes, Green also recognized the importance of the Green Books for African Americans seeking other types of services within cities, including restaurants, bars, barber shops and beauty parlors, pharmacies, and more.

The idea of "The Green Book" is to give the Motorist and tourist a Guide not only of the Hotels and Tourist Homes in all of the large cities, but other classifications that will be found useful wherever he may be. -1947 Edition of the Green Book, pg. 1.

Figure 1 provides an example of the entries in the 1956 Green Book. Establishments were organized by cities within states and, in almost all instances, included exact street addresses. Information on businesses that were friendly towards African Americans spread largely through word-of-mouth. In several instances, Green sourced information from the network of black U.S. postal workers to obtain recommendations from letter carriers across the U.S. Khan, 2015; Taylor, 2020). Businesses could also pay to have an advertisement included in the books. Figure 1(c) includes an example of the types of advertisements that appeared in the publications.

Although many shops and services were included in the Green Books, we document that the vast majority of listings were those providing accommodation, as well as food and beverage establishments (see Figure 2). Publication of the Green Books halted from 1942-1946, when virtually all domestic resources were diverted to sponsoring America's engagement in World War II (Landry, 1988). The books continued to be published until 1966; just one edition was published after the Civil Rights Act outlawed the racial segregation that had

\footnotetext{
${ }^{4}$ To our knowledge there are no known copies of this original Green Book.

${ }^{5}$ See (Loewen, 2009) for a rich discussion of "sundown towns".
} 
once necessitated the Green Books (McGee, 2010). Unfortunately, there is relatively little narrative history of the Green Books at present. Sorin (2009) and Taylor (2020) provide the most comprehensive histories of the Green Books.

\subsection{Digitization and Cleaning}

This paper introduces a county-level panel dataset on the number of establishments that were friendly towards African Americans-those listed in the Green Books-broken down by type of business. Using a combination of hand collection and probabilistic matching techniques we digitize all the entries, including advertisements, in the 21 Green Books that are published in the New York Public Library's (NYPL) Digital Collections.$^{6}$ In particular, we hand-recorded all names, descriptions, and locations, including exact street addresses in most cases, in each edition of the Green Books. These entries were subsequently checked and audited for accuracy. The inconsistent formatting of entries across and within Green Books, largely due to the irregular size and placement of advertisements, and variation in image quality proved to be ill suited for OCR.

After collecting and vetting the data, a combination of probabilistic matching and human verification was used to clean the dataset, which involved matching establishments across years. Idiosyncrasies of the published volumes make it challenging to rely solely on machine learning or probabilistic matching techniques (e.g. Levenshtein or Jaro-Winkler distance) to match observations over time. Table 1 highlights two examples where human judgment is useful.

Example 1 is straightforward: the entry for Fresno Motel had the same name and address between 1957 and 1962, but in the following year its name was slightly different, and the address became more detailed (an intersection instead of simply a street name). For the purposes of geocoding businesses and quantifying openings and closures, identifying these as a match and using the most accurate address are critical, we find that human processing of the data is well poised to exploit contextual information and make this determination.

Example 2 makes the challenges of processing the Green Books data even more apparent. From 1947-52 two related business; "Jim Summers" (a restaurant) and "Summers" (a liquor store) are listed at addresses on Main Street. In 1953, these two businesses disappear, and a similarly named establishment, "Summer's Hotel \& Court" is listed with the address 721 Adams Street. The following year, "Summer Hotel," which has a slightly different street number takes its place. In 1955 the street number changes once again. And over the following two years, either the name or the street address changes. The most likely

\footnotetext{
${ }^{6}$ The complete collection can be found here: https://digitalcollections.nypl.org/collections/ the-green-book
} 
explanation for this pattern is that the proprietor of "Jim Summers" and "Summers" closed these businesses in 1952 and the following year a hotel opened on Adams Street; however, additional contextual information from city directories would be useful for determining if this hotel was owned by the same proprietor as the aforementioned restaurant and liquor store. These types of instances are difficult to match with machine learning or probabilistic matching techniques owing to the changes in addresses and establishment names over the different editions of Green Books.

Another issue that arises is print error. There are instances in which an establishment is listed more than once; sometimes under a "hotels" sub-heading as well as a "general" businesses sub-heading - but the names are ever so slightly different. For example, in the 1955 edition, in Montgomery Alabama "Hotel Ben Moore" with address "Cor. Hight \& Jackson Sts." appears in bold under the hotels sub-heading. Meanwhile, "Ben Moore, Cor. High \& Jackson" also appears under the non-hotel heading. Having a person double check the data that was entered is an effective way of filtering out these types of double entries.

\subsection{Geocoding Greenbook Establishments}

In addition to collecting the list of establishments in each city, we also geocoded their locations for each year. Here we outline the procedure used to geocode each of the Green Book establishment addresses. An initial pass was implemented by running all addresses through the U.S. Census Geocoder.7 This produced either an exact match, a non-exact match, a tie, or no match. Exact matches occur when one unique address is found that matches the input address. About 50 percent of the addresses returned an exact match. Non-exact matches occur if the geocoder was able to locate a similar, but not exact match to the input address. Ties occur when there are more than one addresses that match the input address. In some cases, the geocoder is not able to locate the input address. In the case of a tie or "no match," the input addresses were searched by hand.

A second pass was implemented by hand checking each address in the Green Books in Google Maps. Exact matches that returned latitude and longitude coordinates that were different from the Google Maps coordinates were assumed to be correct if there was less than a one mile difference between the two sets of points (the addresses from the Geocoder and Google Maps). Addresses that were above this threshold were rechecked for typos and historical context. This included addresses that did not return an initial exact match, which were then matched by hand through Google Maps. The remaining missing addresses were imputed using a majority rule. For example, if there was no number associated with a given

\footnotetext{
${ }^{7}$ The Census Geocoder can be found here: https://www. census.gov/geo/maps-data/data/geocoder . html
} 
address, yet the city in which the establishment was located had several establishments on the same street, then the unnumbered address was geocoded in close proximity to the other addresses on that street.

A final high-level error-check was completed by running the coordinates through a feature manipulation engine to verify that they lay within the state boundaries of the state corresponding to the coordinates' entry in the Green Books. About 11 percent of addresses were not able to matched at all, in these instances the centroid of the city was assigned as the geocoded location of the establishment.

Overall, our procedure has distinct advantages over automated approaches. First, as we mention in the previous section, there are idiosyncratic errors in the Green Books that miscode names and locations of businesses in one year. We are able to detect each of these errors and correct the corresponding data to ensure that existing and new firms are appropriately recorded. Second, since our procedure involved checks of addresses against two sources for geocoding, we have a substantially higher match rate than studies such as Akbar et al. (2019), who link addresses over subsequent census enumerations. Third, our method works to ensure that the overall match rate is not driven by urban locations alone, as a failure to accurately account for rural establishments could result in biased inference from the data. A number of Green Book locations are in rural areas, and accurately geocoding them is important for identifying the range of coverage available in the Green Books.

\subsection{Green Book Establishments Over Time}

Figure 3 plots the total number of Green Book establishments listed in each year 8 One striking feature is the sharp drop in the number of Green Book establishments after 1955. This decline was not caused by a reduction in the geographic coverage of the Green Books or an indiscriminate decrease in listings. Figure 4 displays the number of establishments by type: service stations, beauty and barber shops, eating and dining places, formal accommodations, informal accommodations, and other establishments. With the exception of accommodations, all the categories experienced steep declines in the number of listings after 1955. Meanwhile, formal accommodations actually increased throughout the period of publication and informal accommodations declined fairly gradually throughout the post-war period.

One explanation for this is that the publishers of the Green Books simply sought to narrow the focus of the guides towards formal lodging. Figure 5 presents evidence in line with this explanation. Each subplot displays a different industry, where the left vertical

\footnotetext{
${ }^{8}$ We exclude 1937 because it only contained advertisements. In subsequent years, businesses were listed separately based on whether or not they paid for advertisements.
} 
axis indicates the total number of establishments and the right vertical axis is the share of listings that are advertisements. From these figures, it would appear that there was a deliberate attempt to drive up advertising revenue from almost all industries, except formal accommodations.

An alternative explanation is that the Civil Rights movement could have challenged the encouragement of African Americans to patronize specific locales. This issue merits further investigation. But in the absence of a convincing explanation for the drop, we restrict our attention to the pre-1955 period in the analysis that follows. Throughout the remainder of the paper we also employ a number of additional data sources which are discussed as they appear in the paper.

\section{The Expansion of Green Book Establishments Across Regions, Counties, and Cities}

Initially, the Green Book establishments were located in the Southern and Northeastern US, with a small number of businesses open to serving African Americans in the easternmost regions of the Midwest. Figure 6(a) shows the location of all Green Book establishments in 1938, while Figure 6(b) provides a detailed look at establishments in Georgia. By 1955, Green Book establishments were present in every state in the continental US, aside from Montana and North Dakota..$^{9}$ The following subsections investigate the evolution of the number of Green Book establishments in more detail, including regional patterns in Green Book expansion and their relationship to residential housing patterns.

\subsection{Regional Differences}

Figure 7(a) displays the evolution of the number of Green Book establishments in the United States listed in each year between 1939 and 1955. We start our analysis in 1939 since this is the first year with nationwide coverage of the Green Books and we end it in 1955 due to the aforementioned drop in listings, which is not yet well understood. In almost every year, there were over twice as many Green Book establishments in the Northeast compared to the next highest region. This difference is explained by the large quantity of listings in New York City and Newark, where the Green Books originated. Figure 10 displays the geographic dispersion of Green Book establishments per 1000 black residents in 1950. While the Northeast and Midwest certainly appear to have a greater density of Green Book establishments in relation to the African American population, there are a substantial number of counties across the entire US that do not have any Green Book establishments.

\footnotetext{
${ }^{9}$ These states do show up in later editions of the Green Book.
} 
Given that the Green Book listings are establishments, it is important to consider how they relate to measures of population density, as this better captures consumer access to non-discriminatory services. Additionally, the absence of Green Book establishments likely reveals important information about the geography of discrimination. To describe these two together, we create a measure for the existence of a Green Book. If a county does not appear in the Green Books, we infer a count of 0 establishments for that county-year. Next, we construct a balanced-panel of counties for the duration of the Green Book publications. To compute the number of Green Book establishments per capita, we divide the number of establishments by the black population (in 1000s), as measured by the county population estimates for census years in the ICSPR Historical, Demographic, Economic, and Social Data (Haines and Inter-university Consortium for Political and Social Research, 2010). From 1938-1941 we use population in 1940 and from 1947-1955 we use population in 1950.10 Figure $7(\mathrm{~b})$ indicates that, despite the large difference in the number of Green Book establishments between the North and the rest of the country, on a (black) per capita basis; the Midwest and, to a lesser extent, the West, had much higher rates of Green Books penetration.

Apart from the South, which had a similar level of Green Book establishments to the Midwest during this period, all regions experienced an increase in establishments per capita. This is consistent with an interpretation that firms were reluctant to either serve black customers or, at the very least, advertise themselves as welcoming black customers in areas that had high levels of racial animus.

\subsection{Formal Accommodations in the Green Books and the Total Number of Accommodations}

As noted earlier, Figure 4 raises a concern that the process by which firms were being listed in the Green Books may have changed over time. Indeed, the steep drop in listings in 1955 across multiple establishment types indicates that this was the case towards the later part of the sample, but it could be a concern earlier on as well. For this reason, we also consider formal accommodations - hotels and motels - separately. These types of businesses did not experience the steep decline in 1955 and were essentially the raison d'être of the Green Books since the time of their inception. Figure 9 displays the number of formal accommodations across the US Northeast, West, Midwest, and South. While the ranking of regions mirrors that of total establishments, the gap between the Midwest and the rest of the country is significantly smaller. Meanwhile, in contrast to the total establishment count, the number

\footnotetext{
${ }^{10}$ Recall that publication of the Green Books halted during WWII.
} 
of formal accommodation listings has an upward trend across all four regions.

If we consider the number of establishments per 1,000 black residents to be a measure of access to public accommodations, we can learn about the relative access across US regions; this measure is presented in Figure $9(\mathrm{~b})$. The main finding is that hotels and motels are more equally distributed (in per capita terms) across the US than the total number of listings (see Figure 7(a). For the most part, the ranking across regions is similar, with the exception of the West and Midwest which switched places, and are (1) and (2), respectively.

Since areas with a large number of Green Book listings may also be areas with a large number of establishments overall (listed and unlisted), we are also interested in understanding what share of establishments are non-discriminatory. An additional advantage of focusing on formal accommodations is that we can obtain an estimate of this value by digitizing the county-level counts of hotels and motels from the service trade section of the 1935 and 1948 Census of Business. ${ }^{11}$ Figure 8 provides an example of this data source for several counties from the state of Alabama. These counts are available for counties that meet certain population thresholds, so the counties for which we have counts of total accommodations form a subset of the counties for which we have Green Book information. We match our counts of formal accommodations in the Green Books with the counts of all accommodations from the Census of Business to construct the share of non-discriminatory accommodations by county. We use the 1935 Census of Business counts for pre-1941 Green Book years and the 1948 Census of Business counts for post-1947 Green Book years.

Figure 9(c) displays the regional trends in the share of non-discriminatory accommodations. Here we can see that the Northeast has the largest share of non-discriminatory accommodations, while the West had the lowest. Out of all years and regions, the share of non-discriminatory accommodations did not exceed 3 percent, according to our measure.

\subsection{Green Book Business Expansion and Redlined Neighborhoods}

Our final objective is to consider how the location and expansion of Green Book establishments is related to related to local characteristics. In the 1930s, the Home Owners Loan Corporation (HOLC) produced city maps that classified the relative riskiness of lending across neighborhoods. Maps were drawn for over 200 cities, dividing neighborhoods into ratings of $\mathrm{A}$ (least risky) to $\mathrm{D}$ (riskiest) ${ }^{12}$ These maps were used to inform mortgage lenders about the risk-profile of different neighborhoods. As a result, subsequent access to

\footnotetext{
${ }^{11}$ In 1935 information on hotels is published in a separate volume, but in 1948 it is incorporated in the services trade volume.

${ }^{12}$ Some neighborhoods were not given any rating. These were predominantly business districts.
} 
credit was affected by neighborhood clasification.13 We overlay HOLC maps with the exact location of Green Book establishments to determine the grade of the neighborhood in which each establishment is located.14 Fifty percent of Green Book establishments are found in cities for which redlining maps are available.

Figure 11 displays the location of Green Book establishments in 1956 with the HOLC map for Newark and the New York City Burroughs. Visually, it appears that the majority of Green Book establishments are located in redlined neighborhoods. Indeed, out of the establishments that appear in cities for which the georeferenced HOLC security maps are available, an overwhelming majority of them (69 percent) appear in "D-grade" neighborhoods. Approximately 23 percent occur in neighborhoods that did not receive a rating from the HOLC, likely business districts, and only 0.15 percent are located in "A-grade" neighborhoods.15

We examine trends in the number of Green Book establishments by HOLC grade in Figure 12, where it is clear that Green Book establishments expanded most quickly in "D-grade" neighborhoods. Neighborhoods that did not receive a grade, but were located within cities for which we have HOLC security maps also experienced a reasonably large increase in the number of establishments, though by 1955 there were still half as many establishments in "No-grade" neighborhoods in comparison to "D-grade" neighborhoods. "A-grade" neighborhoods experienced almost no growth in Green Book establishments. In fact, in 1955-the year with the highest number of Green Book establishments in "A-grade" neighborhoodsthere were only 6 Green Book establishments in these highest rated neighborhoods out of all cities in the U.S. for which the HOLC security maps are available.

Figure 13 shows how the number of Green Book establishments in each HOLC-grade neighborhood evolved across industry-type. For each industry, the majority of establishments are found in redlined neighborhoods. That being said, the number of Green Book establishments grew in nearly all HOLC-grade neighborhoods and across all industries. Two notable exceptions, include barber shops and gasoline stations, which did not appear in Agrade neighborhoods at any point between 1938 and 1955.

We also present these trends across regions within the US in Figure 14. These results

\footnotetext{
13 Aaronson et al. (2018) provide a thorough discussion of the historical debate surrounding the exact use of HOLC maps by lenders. They find evidence that HOLC classification had causal impacts on homeownership rates, house values, and rents that continue to persist.

${ }^{14}$ The HOLC maps that we use come from the Digital Scholarship Lab at the University of Richmond which digitized and georeferenced HOLC maps for dozens of cities. These are available here: https: //dsl.richmond.edu/panorama/redlining/

${ }^{15}$ Note that we restrict our analysis to establishments that matched exactly in the geocoding procedure, so we are not including establishments that are assigned a latitude and longitude consisting of the centroid of the city, for instance.
} 
largely mirror those in the country-wide plot in Figure 12, with the exception of the US South, which did not have any Green Book establishments in "A-grade" neighborhoods.

Identifying the location of Green Book establishments within cities likely has important implications for understanding the degree to which variation in Green Book establishments reflects differences in black business ownership or differences in discriminatory practices on the part of white owners. Given that the racial composition of a neighborhood was an explicit determinant of the HOLC grade assigned to a neighborhood (Aaronson et al., 2018), Green Book establishments in "D-grade" neighborhoods were more likely to be black-owned compared to those in "No-Grade" (business) districts. Although scholars have discussed the propensity of some white businesses to locate in predominantly black neighborhoods in order to subvert the zoning laws that prevented them from operating in white neighborhoods, these businesses were often in industries that produced negative externalities, such as noise, pollution, or unsightliness- not consumer facing businesses (Rothstein, 2017). It would have been more unusual to find white-owned formal accommodations in predominantly black neighborhoods.16

In the next section, we combine aspects of the previous sections to understand the selection of businesses into the Green Books.

\section{Selection into the Green Books}

One factor that is crucial to understanding the overall spread in Green Book establishments is to understand the process by which establishments entered into the Green Books listings. At the heart of this goal lie two related questions. First, we are interested in understanding whether we can interpret an increase in Green Book listings as an increase in access to public accommodations for black customers, or alternatively whether an increase in listings represents an increase in the propensity to list, perhaps due to an information diffusion process wherein non-discriminatory business owners were increasingly likely to learn about the Green Books over time. Second, we want to know whether the rise in Green Book establishments represent a conscious decision to not to discriminate on the part of white business owners or an increase in black-business ownership.

We begin by focusing on the information diffusion process across counties. We then discuss some of the preliminary work we have done to combine the HOLC grades with newly collected information on whether or not establishments that appear as new listings in the Green Books actually existed in previous years' phone books. Combined with information on red-lining, we expect the latter exercise to inform us on the propensity for black-owned

\footnotetext{
${ }^{16}$ We are currently investigating this distinction by comparing the Green Book establishments to the Negro Business Directory of the State of Wisconsin (1950-1951).
} 
and white-owned businesses to appear in the Green Books over time.

\subsection{Establishment Growth}

A key detail of the Green Book listing process is that listings were crowd-sourced and free for firms. While firms could pay for an additional advertisement, they did not have to pay for inclusion in the Green Books. Victor Green leveraged his employment in the U.S. Postal Service to get recommendations from letter carriers with routes all across the U.S. (Khan, 2015, Taylor, 2020). In addition, the general public, as well as firms, could provide recommendations directly. These features give us some confidence that once there was awareness about the Green Books in a particular county, increases in listings do indeed measure actual increases in access to public accommodations.

An additional consideration is about the interpretation of aggregate trends: is the increase in Green Book listings due to expanded geographic coverage or an actual increase in non-segregated firms in local markets? The first exercise we use to address this issue is to plot the trend in the share of counties with at least one Green Book establishment in Figure 15. In general the trend is not consistent with a model of social learning, which typically follows an S-shaped pattern. It could still be the case that the 1940-1955 time period was one of gradual diffusion and even in the absence of the Civil Rights Act, a more rapid expansion of non-discriminatory establishments would have followed; however, this is not something we are able to empirically evaluate.

Next, we decompose the establishment count into the number of establishments that appear in counties that already had at least one Green Book listing in the previous year and the number that appear in new counties. Figure 16(a) displays this decomposition over time. The figure suggests that the majority of growth in Green Book establishments appeared in counties that already had at least one listing. Thus, if social learning explains some of the rise in Green Book listings, it is likely among businesses that are located within the same counties as existing businesses, and not due to a diffusion process across counties more broadly.

One potential issue with the exercise in Figure 16(a) is that the outcome may be mechanical. As the number of counties with listings increases, we would expect an ever increasing number of new listings to appear in the growing pool of covered counties. To circumvent this issue, we conduct a similar decomposition, this time separating counties into two bins: those that were included in the Green Books in 1939, and those that were not. The results are shown in Figure 16(b). We find that the majority of the increase in Green Book listings occurred in counties that were already listed by 1939-which suggests that the increase in

aggregate Green Book listings is an actual expansion in access to public accommodations 
and not simply an expansion of the geographic coverage of the Green Books.

\subsection{Do Green Books Listings Represent New Entry, Switching, or Increased} Awareness?

A fundamental question is how to interpret the growth of business listings in the Green Books. Does this increase represent a rise in black-friendly business (new entry), and if so, is this explained by black-owned businesses; a conscious decision not to discriminate on the part of white businesses owners (switching); or simply firms that were not discriminating becoming aware of the Green Books and getting listed (awareness)? Essentially, we want to understand at a more granular level whether local businesses are learning about the Green Books or if they are indeed becoming non-discriminatory. For instance, a firm in one period may be non-discriminatory but is not aware that the Green Books exist as a mechanism for advertising their business and it decides to advertise once aware. To partially mitigate this concern, we can restrict our analysis to firms that do not advertise (since the Green Books included regular listings and paid advertisements, we use only firms listed in the directory which was not a function of advertising). However, this does not rule out the possibility that the Green Book editors are also learning about which firms are nondiscriminatory. An innovation we propose to deal with this question is to hire researchers to look up businesses in historical phone books and city directories located at the Library of Congress. These phone books are not available online and the majority are available on microfilm, only. This process will allow us to determine whether a business that is new to the Green Books in one year existed in the previous year, and since we have the geocoded address of each Green Book establishments we can examine whether this occurs disproportionately in neighborhoods rated higher or lower by the HOLC, which we consider to have informational content about the ownership of the business as red-lined areas were predominantly served by black businesses. By comparing the tenure of firms in the Green Books by year and HOLC grade, we expect to gain insight into the change in propensity of non-discriminatory establishments to be listed in the Green Books over time compared to the change in the propensity of black businesses to develop over time.

As a preliminary check, we hired two researchers with experience working with the Library of Congress phone book collections to complete this procedure for a small sample of cities and years. Our researchers examined 191 Green Book entries from Atlanta, Los Angeles, New York City, and St. Louis in 1941 and 1940; and 407 Green Book entries from

Atlanta and New York City in 1948 and 1947. In the 1941 sample, 85 establishments (44 percent) were new to this edition of the Green Book but were not new businesses (i.e., they appeared in the 1940 phone books). In our 1948 sample, 147 establishments (36 percent) 
were new Green Book listings but were located in the 1948 and 1947 phone books. This is consistent with no measurable change, or even a slight decrease, in the likelihood that an existing firm would become listed in the Green Books over time. We also find that by red-lined location, new Green Book establishments were increasingly likely to be located outside of redlined, "hazardous" neighborhoods (HOLC grade of D). In 1941, 14 percent of the new establishments listed in the Green Books were in non-hazardous neighborhoods, in 1948, 21 percent of the new Green Book establishments were located in non-hazardous neighborhoods, suggesting that new locations were less likely to be located in predominantly black neighborhoods over time.

Going forward, we will examine the demographics of these neighborhoods in more detail using information from the 1940 and 1950 Censuses of Population regarding racial composition at the census tract level. We believe our preliminary analysis using redlining maps highlights the potential of this methodology for disentangling the growth in new listings due to changes in discriminatory attitudes and geographic expansion of accommodations versus the growth in new listings due to businesses learning about the value of listing in the Green Books.

\section{Correlates of Green Book Establishments}

As a final objective of this paper, we seek to understand the correlates of Green Book presence. At the county level, we consider measures of economic development, such as education, involvement in manufacturing, and WWII military contracting; as well as other measures of segregation and discrimination that have traditionally been used in the literature, like residential segregation, lynching, and Confederate symbols. We also introduce a new state-level dataset that consists of the number of discrimination and anti-discrimination laws passed by states as of 1950 .

\subsection{County Characteristics and the Presence of Green Book Establishments}

Figures 17 to 22 present elasticities of the number of Green Book establishments and the set of aforementioned factors. All regression specifications are estimated at the county levele.g., number of Green Books listings by county-and both the dependent and independent variables have been transformed using the inverse hyperbolic sine function so that they can be roughly interpreted as elasticities ${ }^{17}$ Many of the factors we examine may also be correlated with city size, economic activity, and consequently the number of establishments in a given county more generally, these unobservables may have the potential to bias our

\footnotetext{
${ }^{17}$ We use the arcsinh transform instead of a log-log specification due to the presence of a large number of zeros in the dependent variable, as many counties did not have any Green Book listings.
} 
coefficient estimates. Fortunately, by focusing on the set of formal accommodations listed in the Green Books, we can check whether conditioning on the total number of accommodations affects these correlations.

In all figures, elasticities using all Green Book establishments are represented by squares; estimates restricted to using formal accommodations are represented by circles; estimates restricted to using formal accommodations and restricting to the sample of counties for which we also have Census of Business estimates are represented by triangles; and estimates restricted to using formal accommodations and conditioning on Census of Business estimates are represented by diamonds. Ultimately, we are interested in understanding whether conditioning on the total number of accommodations from the Census of Business affects our results; however, we impose each of our restrictions and specification changes in sequence so that we are able to assess which of the three additional specifications are driving the changes in coefficient estimates.

We begin with Figure 17 by showing these elasticities for a set of characteristics that we take from the 1940 complete count census (Ruggles et al., 2019). Unconditionally, a one percent increase in the black population is associated with a precise 0.1 percent increase in the number of Green Book establishments. This coefficient estimate is halved once we restrict to formal accommodations, and then remains stable using the sample for which we have Census of Business estimates, as well as conditioning on the number of Census of Business accommodations. The remainder of the elasticities are estimated conditional on the black population.

Given that the Green Book listings were sourced through a network of postal workers, we may expect places with a higher number of black postal workers to also have more Green Book establishments. Indeed, we find that, conditional on the black population, a one-percent increase in the number of black postal workers is associated with a nearly 0.5 percent increase in the number of Green Book establishments. ${ }^{18}$ This finding suggests that any analyses that use the Green Books should be mindful of this correlation and account for it in empirical specifications. Again, restricting to formal accommodations approximately halves this elasticity estimate, and it remains stable thereafter.

Another factor that may be an important correlate of the presence of Green Book establishments is the presence of black migrants within a county. Reminiscent of shift-share instruments in the migration literature (Boustan, 2009, Derenoncourt, 2019), the share of black migrants in 1940 may be correlated with the presence of Green Book establishments if the presence of migrants tends to attract more migrants. As such, we also consider the

\footnotetext{
${ }^{18}$ We compute the number of black postal workers by summing over the number of black mail carriers, post masters, and express messengers and railway mail clerks.
} 
relationship between Green Book presence and the share of the black population who are migrants from out of state, as well as the share of the black population who are migrants from within state ${ }^{19}$ Unconditionally, the presence of both types of migrants is positively correlated with the number of Green Book establishments; however, in both cases restricting to an analysis of formal accommodations more than halves our coefficient estimates, and in the case of between state migration, the coefficient becomes negative once we condition on the Census of Business hotels. That being said, the share of migrants within state remains precisely estimated and positively correlated with the number of Green Book establishments.

Figure 18 examines the relationship between educational attainment and the presence of Green Book establishments. We estimate the elasticities of Green Book establishments with respect to the share of the black and white population aged 15-65 with no formal education, with at least 5 grades of schooling, and with at least 10 grades of schooling. Overall, it appears that having both an education black and white population is associated with a higher presence of Green Book establishments, while a greater share of the adult population with no education is negatively correlated with the presence of Green Book establishments. These estimates are mostly robust to all sample restrictions and to conditioning on the number of formal accommodations from the Census of Business, although the latter specification is less precisely estimated.

In the next figure, we examine the correlation between county level household characteristics and the presence of Green Book establishments. We use household characteristics to proxy for wealth or well-being. Figure 19 shows that Green Book presence is negatively correlated with the percent of blacks who own their own dwelling, which may not be surprising if the presence of Green Book establishments is also correlated with other segregation or discrimination laws that prevented African Americans from participating in lending markets, for instance. That being said, this correlation is not statistically different from zero and changes very little once we impose our sample restrictions and condition on the Census of Business estimates.

Other measures of material well-being, such as the percent of all households who have an electric light, radio, or fridge in their dwelling are all positively correlated with the presence of Green Book establishments, but are substantially reduced in magnitude, and some of which are statistically insignificant once we condition on the number of accommodations from the Census of Business. It is important to note here that the reduction in the magnitude of the coefficient estimates is partly due to the focus on accommodations, and partly due to conditioning on the Census of Business estimates.

\footnotetext{
${ }^{19}$ We do not condition on the black population in these specifications because the black population is the denominator for the share of black migrants.
} 
Turning to other proxies of economic activity in Figure 20 tell a similar narrative. Green Book establishments appear more prominently in areas with more involvement in manufacturing, as measured by total manufacturing wages, establishments, wage earners, output, and value added; however this result is also reduced in magnitude once we focus on formal accommodations, and is further reduced when we condition on the total number of accommodations from the Census of Business. US federal government World War II contracts also tend to be associated with more Green Book establishments. In Figure 21 we show the elasticities of Green Book establishments with respect to war contracts for the supply of combat equipment, other types of supplies, industrial facilities contracts, and military facilities contracts. In each instance a one-percent increase in the number of contracts is associated with a 0.04-0.05 percent increase in the number of Green Book establishments. Again, these elasticities are reduced in magnitude to below 0.01 percent and are, at times, marginally statistically significant after conditioning on the total number of accommodations.

Overall, the elasticities of the number of Green Book establishments with respect to various measures of economic activity are generally positive and statistically significant, but are reduced in magnitude and precision when we condition on the total number of accommodations. Although this change is partially attributed to sample restrictions we have to impose in order to estimate the conditional elasticities, the majority of the reduction in coefficient magnitudes can be attributed to the inclusion of the total number of accommodations. This result suggests that places that have higher levels of economic activity may be marginally less discriminatory, but are often just areas with more businesses to begin with.

Figure 22 examines the relationship between segregation in public accommodations and residential segregation. We present the elasticities of Green Book establishments with respect to three measures of residential segregation: the dissimilarity index, the isolation index, and the Logan-Parman segregation index 20 All three measures are obtained from Logan and Parman (2017). Unconditionally, we find areas with a higher Green Book presence tend to be areas that are also more segregated residentially (higher values of all three of the segregation indices indicate higher segregation). The elasticities constructed using all three indices remain positive and statistically significant when we restrict to formal accommodations and when we restrict to the Census of Business sample. With the exception of the dissimilarity index, we also find the elasticities are positive after conditioning on the total

\footnotetext{
${ }^{20}$ The dissimilarity index measures the similarity of the distribution of minority residents to that of non-minority residents within a geographic unit, effectively comparing the percentage of black residents to the percentage of white residents within the geographic unit. The isolation index measures the "extent to which minority members are exposed only to one another" (Massey and Denton, 1988). The LoganParman segregation index provides an alternative to these two measures, which may be especially suitable for historical data. Within a census enumeration, this index uses the location and race of households in adjacent units to measure segregation in the community.
} 
number of hotels from the Census of Business. We conclude from this figure that areas with greater levels of residential segregation generally have more Green Book establishments.

In Figure 23, we examine the relationship between the presence of Green Book establishments and a darker part of American history. Here, we display the elasticities for a number of proxies for racial animus or discrimination. In line with the work of Williams (2019), we use the number of Confederate symbols in a county. ${ }^{21}$ First, counties with more Green Book establishments also have more Confederate symbols - statues, plaques, and roads or public building named in honour of Confederate soldiers and politicians. Although there is a gain in precision when formal accommodations are considered separately, the correlation with Confederate symbols is largely unchanged across specifications.

Next, we consider the relationship between Green Book establishments and historical violence against blacks, captured by the cumulative number of black lynchings in a county, up to 1936. These measures are from the database collected in Cook (2012a) and expanded on more recently. We find, conditional on the black population, lynchings against blacks to be be negatively correlated with the total count of Green Book establishments.22 The point estimate for black lynchings is negative across all four specifications. That said, the elasticity between formal Green Book accommodations and historical lynchings of blacks is smaller in magnitude than the elasticity between all Green Book establishments and historical lynchings of blacks. This estimate changes little when we restrict to counties that also have Census of Business estimates, but we cannot reject that the correlation is zero at the 10 percent significance level when we condition on the total number of formal accommodations. Finally, we find a small positive elasticity of Green Book establishments with respect to White Lynchings; however, this estimate is marginally significant and is a precisely estimated 0 when we impose any of the sample restrictions.

In light of the impact that conditioning on the total number of firms has on the estimated elasticities, we conclude that the local level of market competition (as measured by the number of firms) played an important role in the provision of public accommodations to African American customers during this period, and should be taken into account in any empirical analysis using the Green Books data.

\footnotetext{
${ }^{21}$ The Confederate symbols are collected from the Southern Poverty Law Centre's collection: https: //www.splcenter.org/20190201/whose-heritage-public-symbols-confederacy.

${ }^{22}$ It turns out without conditioning on the black population, historical lynchings is positively correlated with the presence of Green Book establishments. These results are unreported, but available upon request.
} 


\subsection{State-Level Discrimination Laws and the Presence of Green Book Es- tablishments}

This section evaluates the relationship between the presence of Green Book establishments and state-level variation in laws relating to discrimination. In 1950, African American activist and lawyer, Pauli Murray, published a volume, titled, "States' Laws on Race and Color." Murray's 746-page book, which Thurgood Marshall later termed the "bible" of Brown v. Board of Education, listed all the laws passed in the United States that were related to segregation and discrimination ${ }^{23}$ We digitize all entries in "States' Laws on Race and Color" to construct a state-level dataset of the number of laws passed related to segregation or discrimination. For our purposes, we focus on anti-discrimination laws and discriminatory laws ${ }^{24}$ As an example of an anti-discrimination law described in Murray (1950), in 1944 the state of Maine passed a statute prohibiting life insurance companies from discriminating between individuals of the same class of insurance risk. Alternatively, an example of a law upholding discrimination includes a statute from Maryland passed in 1935 that prohibited marriage between whites and African Americans.

We present scatter plots of the relationship between the number of discriminatory laws by 1950 and the number of Green Book establishments in 1950 in Figure 24. A linear regression of the number of Green Book establishments on the number of discriminatory laws produces a slope coefficient of 0.45 , suggesting that an additional discriminatory law is associated with nearly 0.5 more Green Book establishments, on average. Interestingly, we also find a positive correlation between anti-discrimination laws and the number of Green Book establishments in Figure 25. With a slope coefficient of 3.13, this relationship is much stronger, suggesting an additional anti-discrimination law is associated with just over 3 more Green Book establishments.

The fact that both anti-discrimination and discriminatory laws are positively correlated with the number of Green Book establishments presents a puzzle, which can partially be addressed by a breakdown of these correlations by industry. Figures 26 and 27 display these plots. Beginning with the industry-level plots for discriminatory laws in Figure 26 reveals that informal accommodations may be driving the positive correlation between Green Book establishments and discriminatory laws in Figure 24. Intuitively, we might expect a large number of informal accommodations to arise in areas with a greater level of de

\footnotetext{
${ }^{23}$ See the description in The New Yorker's "Many Lives of Pauli Murray": https://www.newyorker. com/magazine/2017/04/17/the-many-lives-of-pauli-murray.

${ }^{24}$ Both anti-discrimination and discriminatory laws include acts of assembly, assembly bills, constitutional changes, executive orders, general acts, house bills, house resolutions, joint resolutions, regional compacts, resolutions, and statutes.
} 
jure segregation or discrimination. Turning to formal accommodations, eating and drinking establishments, and barber and beauty shops we see almost no relationship between discrimination laws and the number of Green Book establishments. On the other hand, Figure 27 shows a strong, positive correlation between the number of anti-discrimination laws and Green Book establishments for all industries.

\section{Conclusion}

The Green Books present an unprecedented historical account of segregation in public accommodations during Jim Crow. By digitizing and geocoding the location of all establishments listed in these publications, we are able to provide new insights into the geography and correlates of this type of discrimination. While the number of non-discriminatory public accommodations increased nationwide between 1939 and 1955, this growth was largest in the Northeast. On a per-capita basis (based on the number of African American residents), the midwest vastly exceeded the rest of the country over this same time period in terms of access to non-discriminatory public accommodations. Combining our counts of Green Book formal accommodations with newly digitized values of the number of accommodations by county across the United States reveals that the Northeast also had the largest share of non-discriminatory public-accommodations. Within cities, Green Book establishments were disproportionately located in areas that were traditionally excluded from lending markets due to the practice of redlining, wherein the Home Owner's Loan Corporation drew residential security maps which cautioned lenders from providing loans in certain neighborhoods.

In general, the presence of Green Book establishments is positively correlated with a wide range of factors that proxy for economic activity: educational attainment, household characteristics like having an electric light, radio, or fridge, involvement in manufacturing, and the number of WWII contracts. That being said, many of these correlations are reduced substantially when we restrict our analysis to formal accommodations and condition on the total number of accommodations from the U.S. Census of Business. Thus, the presence Green Book establishments appears to be positively correlated with economic activity insofar as economic activity generates businesses more broadly, and likely not entirely due to a fundamental difference in the propensity to discriminate in these areas.

Overall, our analysis presents several new facts related to access to non-discriminatory public accommodations during the pre-Civil Rights Act era, which had previously been undocumented. We also provide a series of recommendations for researchers wishing to use the Green Book data moving forward. 


\section{References}

Aaronson, D., D. Hartley, and B. Mazumder (2018). The effects of the 1930s HOLC "redlining" maps. Working Paper.

Akbar, P. A., S. Li, A. Shertzer, and R. P. Walsh (2019). Racial segregation in housing markets and the erosion of black wealth.

Ananat, E. O. (2011). The wrong side(s) of the tracks: The causal effects of racial segregation on urban poverty and inequality. American Economic Journal: Applied Economics 3(2), 34-66.

Ananat, E. O. and E. Washington (2009). Segregation and black political efficacy. Journal of Public Economics 93(5-6), 807-822.

Boustan, L. (2009). Competition in the promised land: Black migration and racial wage convergence in the North, 1940-1970. The Journal of Economic History 69(3), 756-783.

Brown, D. L. (2017, June 1). Life or death for black travelers: How fear led to 'The Negro Motorist Green-Book'. The Washington Post. Accessed: Oct. 2, 2017.

Card, D. and J. Rothstein (2007). Racial segregation and the black-white test score gap. Journal of Public Economics 91(11-12), 2158-2184.

Cook, L. D. (2012a). Converging to a national lynching database: Recent developments and the way forward. Historical Methods 45(2), 55-63.

Cook, L. D. (2012b). Overcoming discrimination by consumers during the age of segregation: The example of Garrett Morgan. Business History Review 86(2), 211-234.

Cutler, D. M. and E. L. Glaeser (1997). Are ghettos good or bad? The Quarterly Journal of Economics 112(3), 827-872.

Derenoncourt, E. (2019). Can you move to opportunity? Evidence from the Great Migration. Working Paper.

Gil, R. and J. Marion (2019). Why did firms practice segregation? Evidence from movie theaters during Jim Crow.

Haines, M. R. and Inter-university Consortium for Political and Social Research (2010, 5). Historical, demographic, economic, and social data: The United States 1790-2002.

Khan, E. M. (2015, Aug). The 'Green Book' legacy, a beacon for black travelers. New York Times.

Landry, B. (1988). The New Black Middle Class. University of California Press.

Loewen, J. W. (2009). Sundown towns and counties: Racial exclusion in the south. Southern Cultures 15(1), 22-47. 
Logan, T. D. and J. M. Parman (2017). The national rise in residential segregation. The Journal of Economic History 77(1), 127-170.

Massey, D. S. and N. A. Denton (1988). The dimensions of residential segregation. Social Forces 67(2), 281-315.

McGee, C. (2010, Aug. 22). The open road wasn't quite open to all. The New York Times. Accessed: Oct. 1, 2017.

Murray, P. (Ed.) (1950). States' Laws on Race and Color. Cincinnati, Woman's Division of Christian Service, Board of Missions and Church Extension, Methodist Church.

Roback, J. (1986). The political economy of segregation: The case of segregated streetcars. The Journal of Economic History 46(4), 893-917.

Rothstein, R. (2017). The Color of Law. New York, NY: Liveright Publishing Corporation.

Ruggles, S., S. Flood, R. Goeken, J. Grover, E. Meyer, J. Pacas, and M. Sobek (2019). IPUMS USA: Version 9.0 [dataset]. Minneapolis, MN: IPUMS, 2019. https://doi.org/10.18128/D010.V9.0.

Sorin, G. S. (2009). "Keep Going:" African Americans on the Road in the Era of Jim Crow. Ph. D. thesis, University at Albany, State University of New York.

Sugrue, T. J. (2010). Driving while black: The car and race relations in modern america. Accessed: Oct.2, 2017.

Taylor, C. (2020). Overground Railroad: The Green Book and the Roots of Black Travel in America. New York, NY: Abrams Press.

Wilkerson, I. (2010). The Warmth of Other Suns. Vintage Books.

Williams, J. (2019). Confederate streets and black-white labor market differentials. Working Paper. 


\section{A Tables}

Table 1: Idiosyncratic Greenbook Entries

\begin{tabular}{|c|c|c|c|c|c|}
\hline Example & Year & Establishment & Address & City & Type \\
\hline \multirow[t]{2}{*}{ Fresno Motel } & $1957-1962$ & Fresno Motel & Hwy. 99 & Fresno, CA & Lodging \\
\hline & 1963 & $\begin{array}{l}\text { Fresno } \\
\text { Hacienda }\end{array}$ & $\begin{array}{l}\text { Hwy. } 99 \text { and } \\
\text { Clinton }\end{array}$ & Fresno, CA & Lodging \\
\hline \multirow[t]{7}{*}{ Summer's Hotel \& Resto. } & $1947-52$ & Jim Summers & $\begin{array}{l}719 \\
\text { S. Main St }\end{array}$ & Camden, AR & Restaurant \\
\hline & " & Summers & $\begin{array}{l}715 \\
1 / 2 \text { S. Main Street }\end{array}$ & Camden, AR & Liquor store \\
\hline & 1953 & $\begin{array}{l}\text { Summer's } \\
\text { Hotel \& Court }\end{array}$ & $\begin{array}{l}721 \text { Adams } \\
\text { Street }\end{array}$ & Camden, AR & Lodging \\
\hline & 1954 & Summer Hotel & $\begin{array}{l}7541 / 2 \text { Adams } \\
\text { St. S. W. }\end{array}$ & Camden, AR & Lodging \\
\hline & 1955 & Summer Hotel & $\begin{array}{l}740 \text { Adams } \\
\text { Ave. S.W. }\end{array}$ & Camden, AR & Lodging \\
\hline & 1956 & $\begin{array}{l}\text { Summers Hotel } \\
\text { \& Restaurant }\end{array}$ & $\begin{array}{l}740 \text { Adams } \\
\text { Avenue S.W. }\end{array}$ & Camden, AR & $\begin{array}{l}\text { Lodging \& } \\
\text { Resto. }\end{array}$ \\
\hline & 1957 & $\begin{array}{l}\text { Summer's } \\
\text { Hotel \& Motel }\end{array}$ & $\begin{array}{l}750-7541 / 2 \\
\text { Adams Ave. }\end{array}$ & Camden, AR & Lodging \\
\hline
\end{tabular}




\section{B Figures}

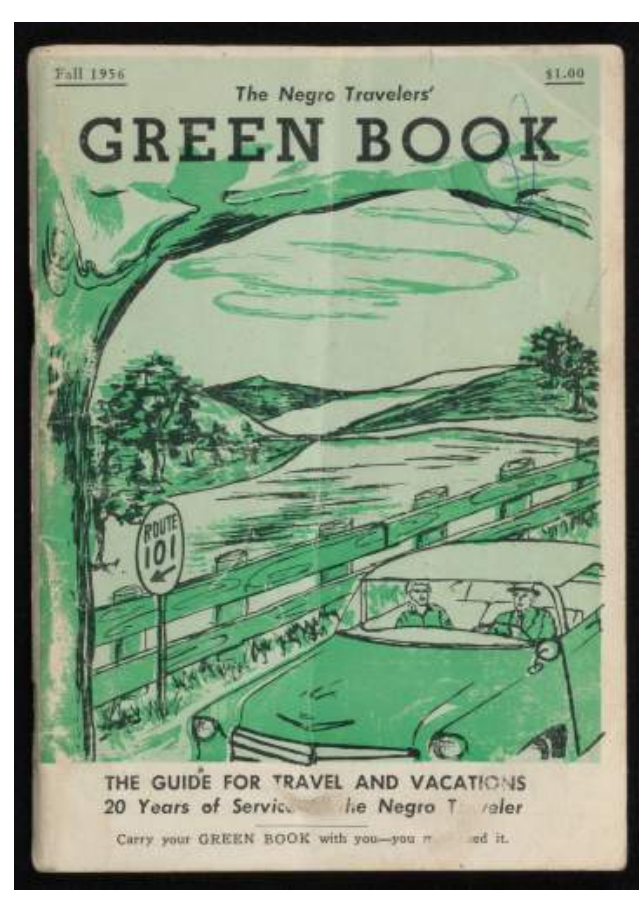

(a) Front page

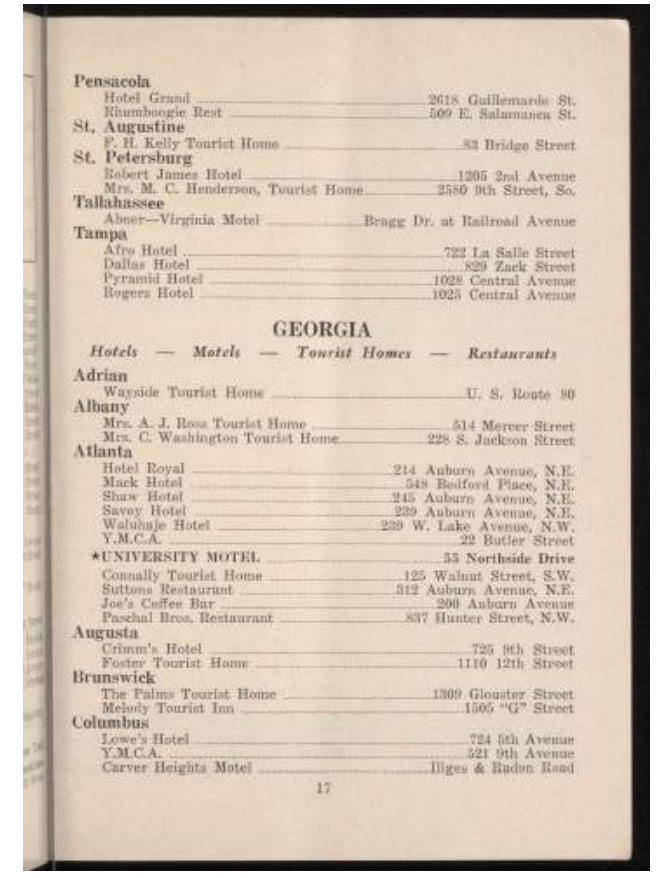

(b) Example from Georgia

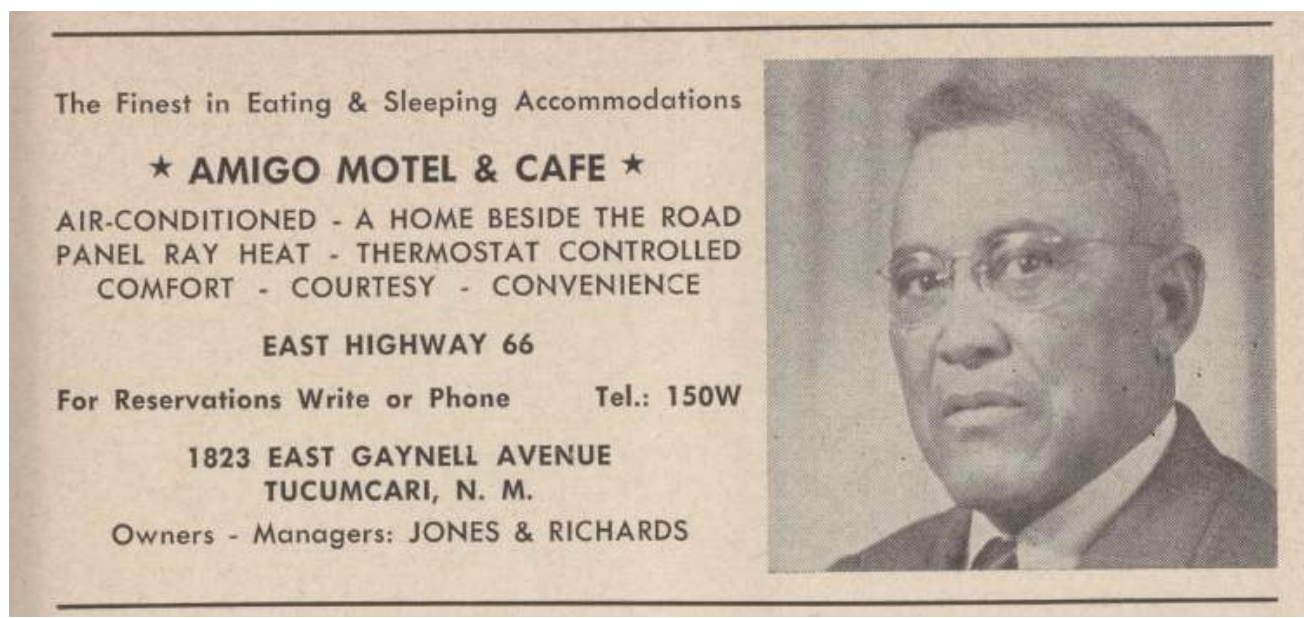

(c) Example of an advertisement

Figure 1: Sample of the Green Book publications from the year 1956 and the state of Georgia. Reproduced from the New York Public Library Digital Collections. 


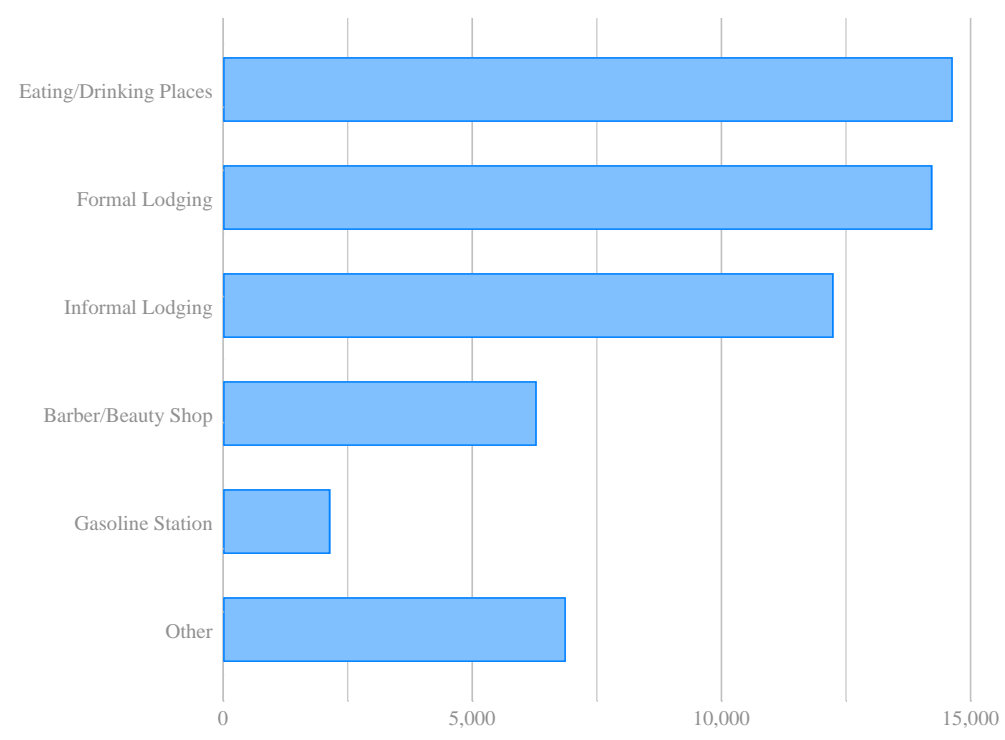

Figure 2: Frequency of establishments in all years listed by type of establishment. 


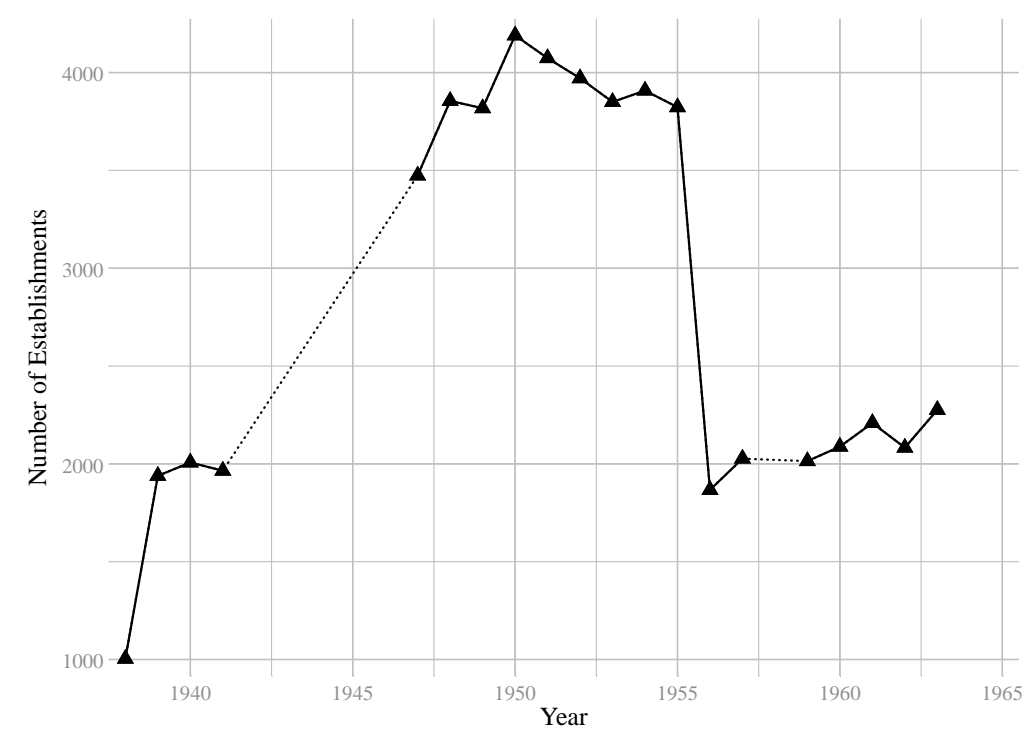

Figure 3: Number of Green Book establishments listed for the United States in each publication of the travel guides. 


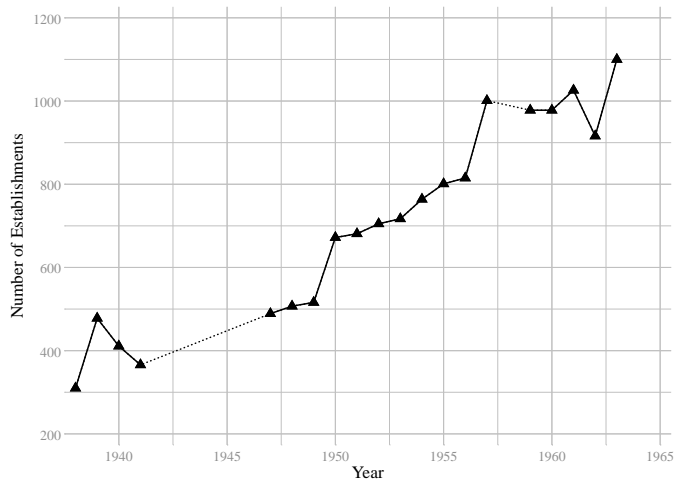

(a) Formal Accommodations

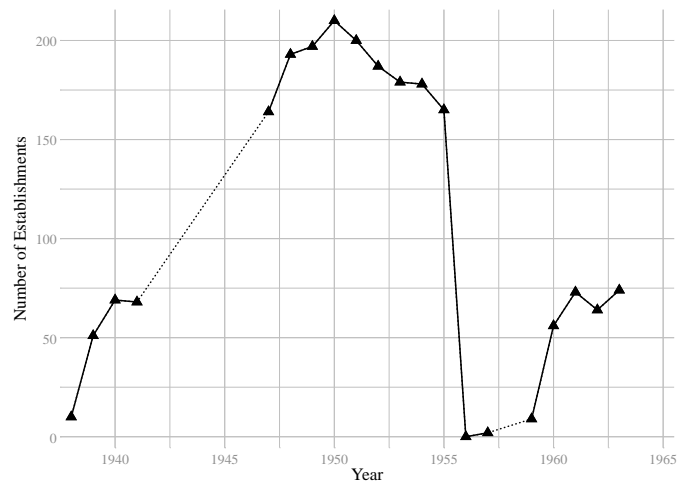

(c) Service Stations

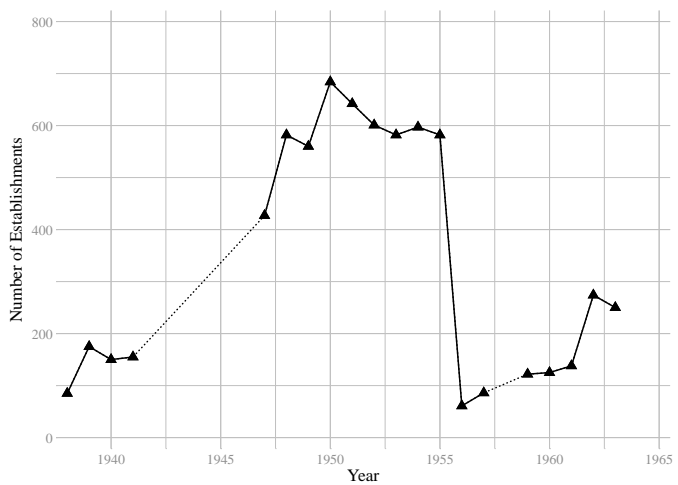

(e) Other

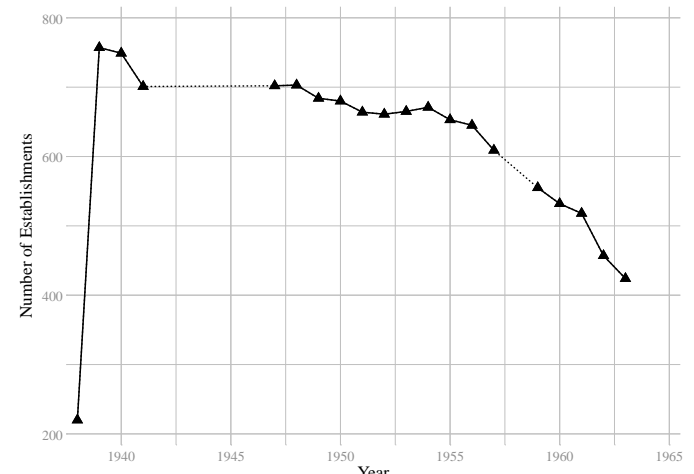

(b) Informal Accommodations

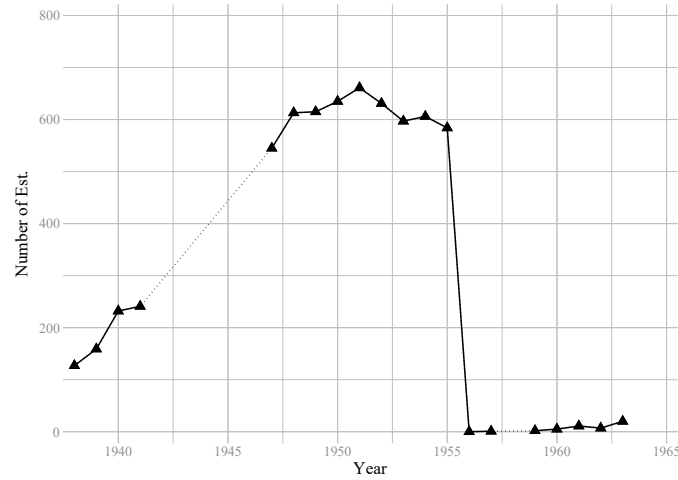

(d) Beauty and barber shops

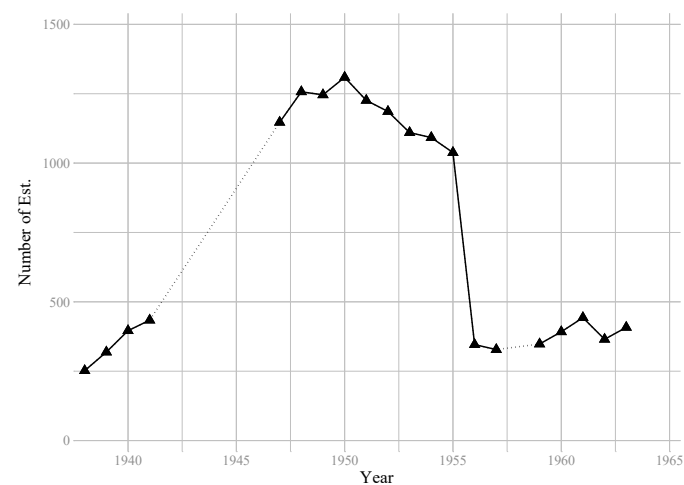

(f) Eating and dining

Figure 4: Number of Green Book establishments listed for the United States in each publication of the travel guides. Each subplot displays a different establishment category. Beauty and barber shops also include beauty schools; Eating and dining include all restaurants and cafes; Formal accommodations include hotels and motels; Informal accommodations includes tourist homes, boarding houses, camps, and other lodging; Other includes all other establishments that did not fit clearly into one of the above categories. 


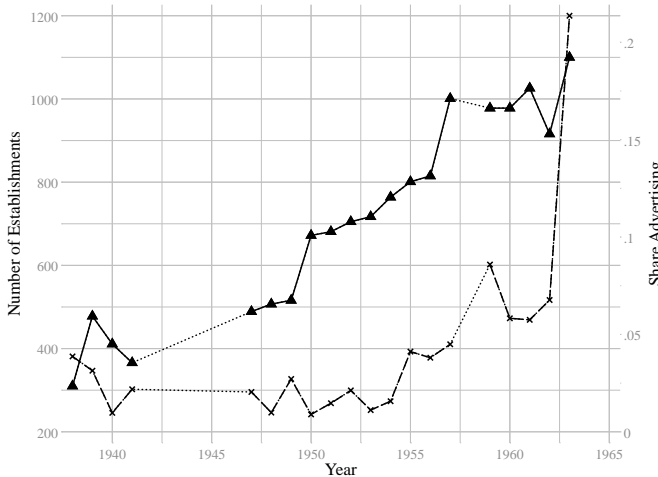

(a) Formal Accommodations

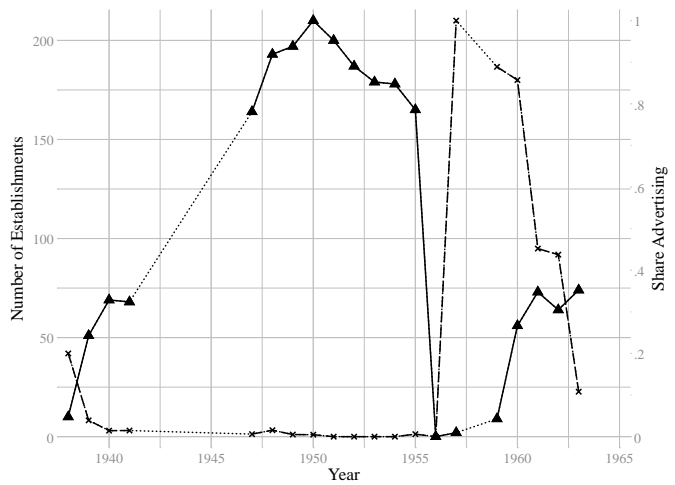

(c) Service Stations

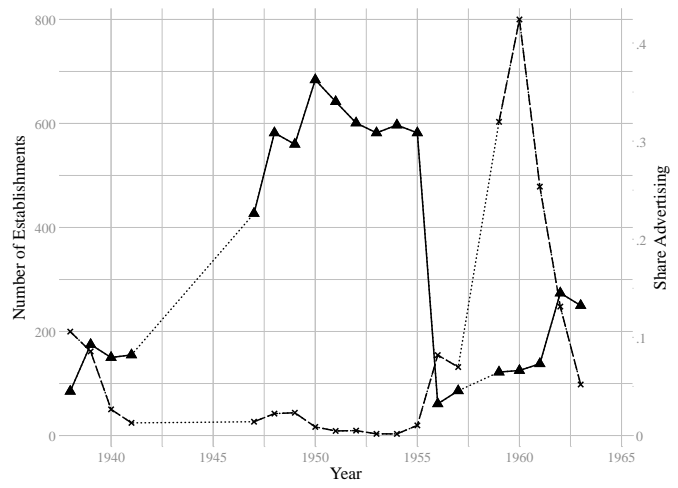

(e) Other

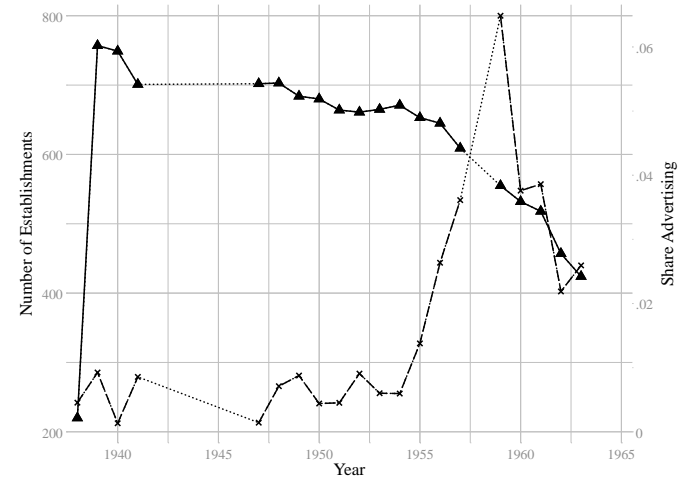

(b) Informal Accommodations

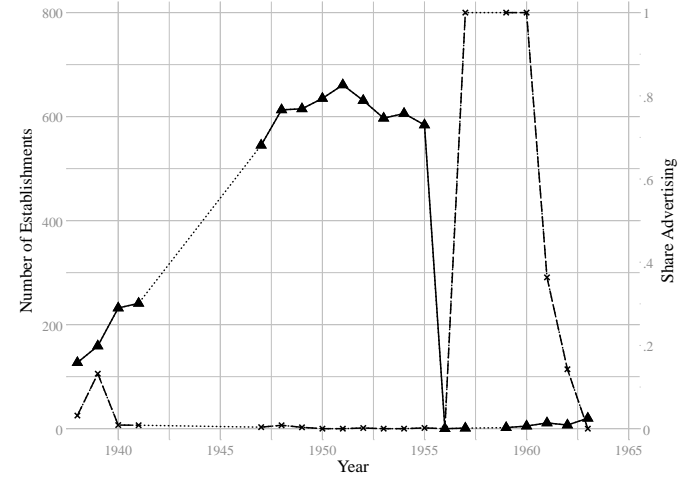

(d) Beauty and barber shops

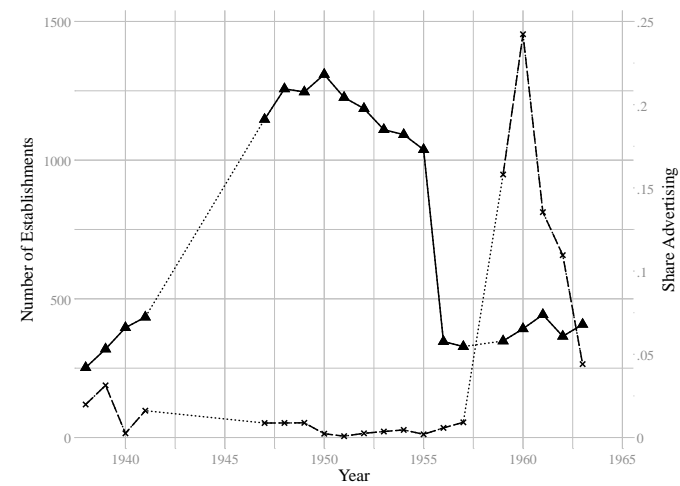

(f) Eating and dining

Figure 5: Number of Green Book establishments listed for the United States in each publication of the travel guides. Each subplot displays a different establishment category, as well of the share of listings of that category that were advertisements. Beauty and barber shops also include beauty schools; Eating and dining include all restaurants and cafes; Formal accommodations include hotels and motels; Informal accommodations includes tourist homes, boarding houses, camps, and other lodging; Other includes all other establishments that did not fit clearly into one of the above categories. 


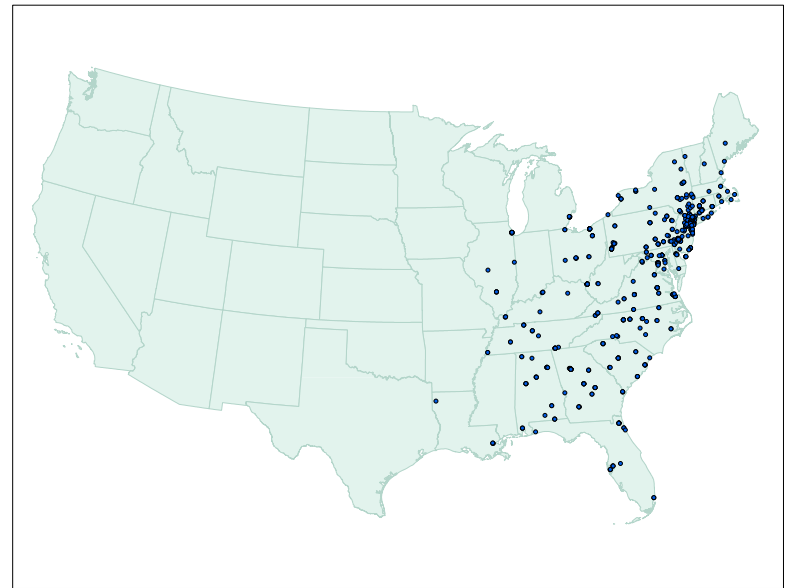

(a) All Green Book locations in continental USA (1938)

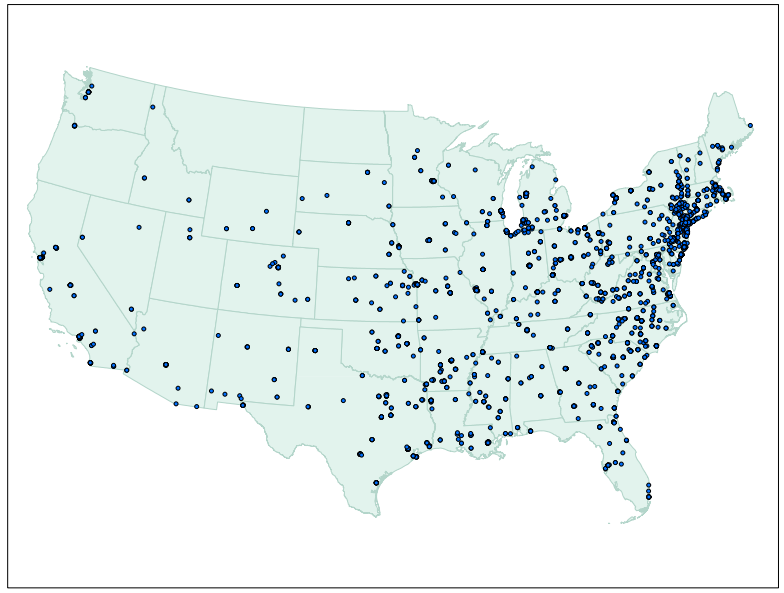

(c) All Green Book locations in continental USA (1955)

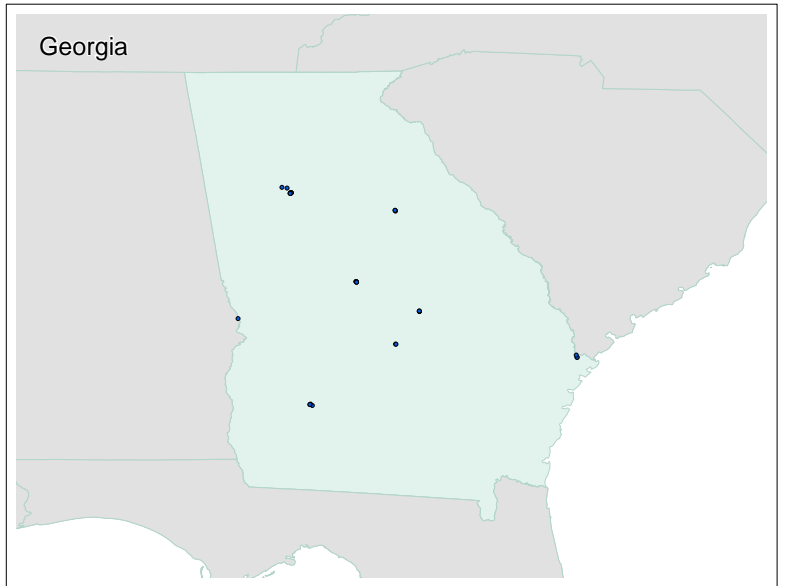

(b) All Green Book locations in Georgia (1938)

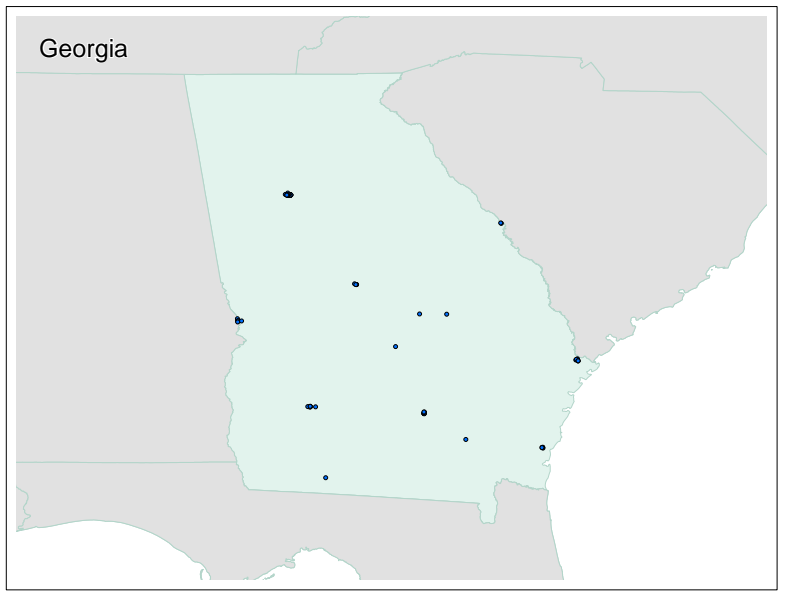

(d) All Green Book locations in Georgia (1938)

Figure 6: Location of Green Book establishments in 1938 and 1955 in continental USA and state of Georgia. 


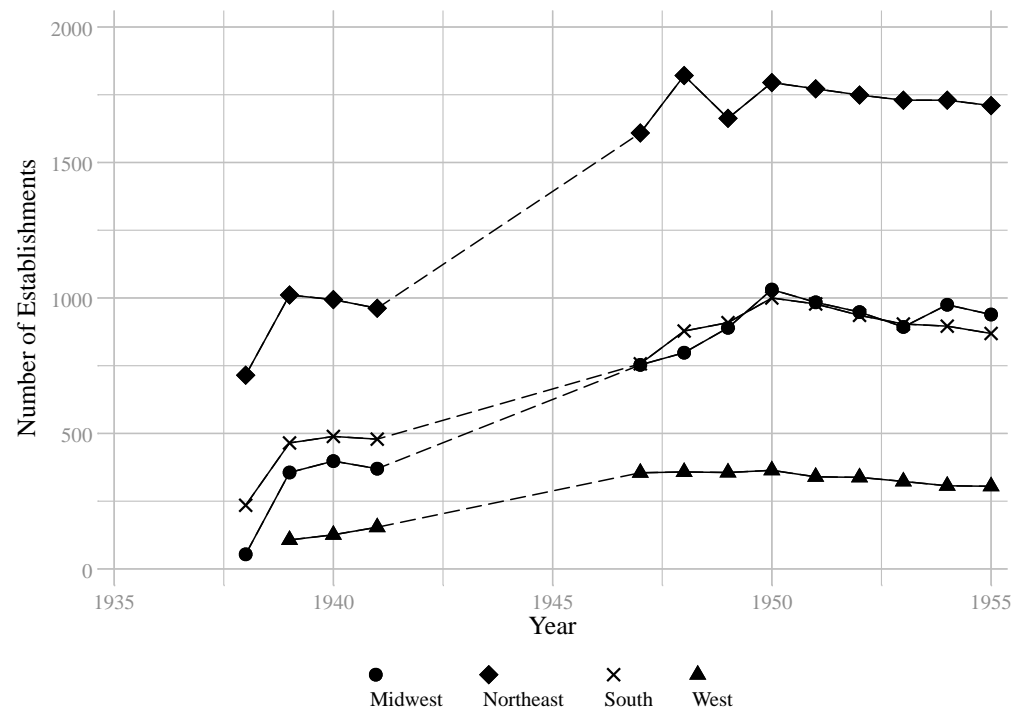

(a) Number of establishments, regional breakdown

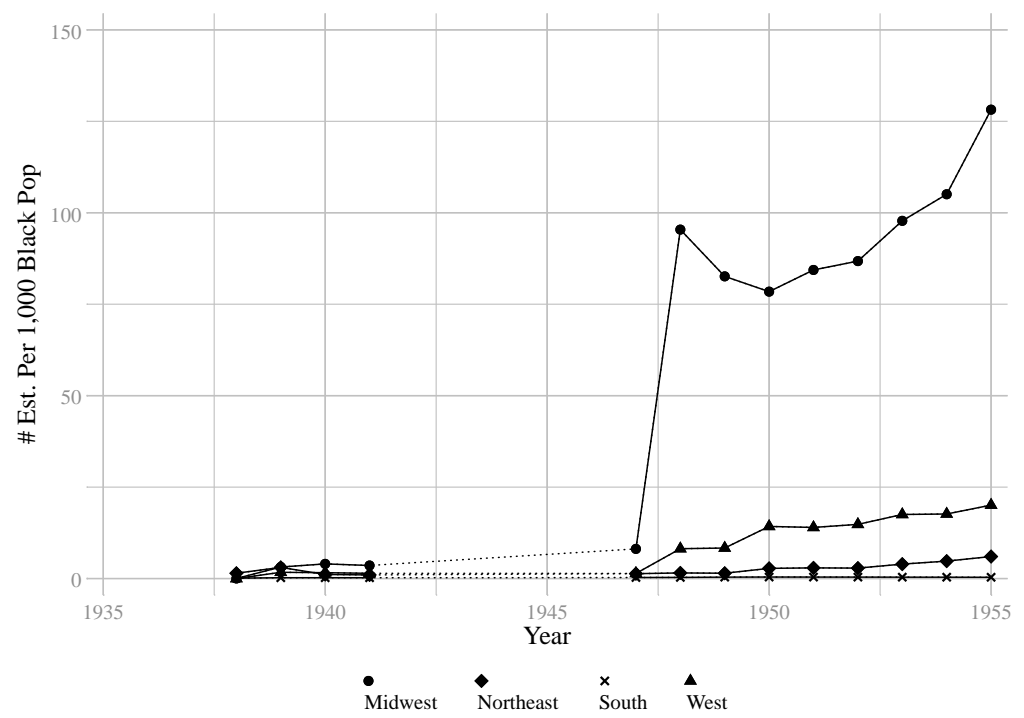

(b) Establishments by black population, regional breakdown

Figure 7: The evolution of Green Book establishments by region. 


\begin{tabular}{|c|c|c|c|c|c|c|}
\hline State and County & $\begin{array}{l}\text { Num- } \\
\text { ber } \\
\text { of } \\
\text { Estab- } \\
\text { lish- } \\
\text { ments }\end{array}$ & $\begin{array}{c}\text { Total } \\
\text { number } \\
\text { of } \\
\text { guest } \\
\text { rooms }\end{array}$ & $\begin{array}{l}\text { Receipts } \\
\text { (add } 000 \text { ) }\end{array}$ & $\begin{array}{l}\text { Active } \\
\text { pro- } \\
\text { prie- } \\
\text { tors } \\
\text { and } \\
\text { firm } \\
\text { mem- } \\
\text { bers }\end{array}$ & $\begin{array}{c}\text { Employ- } \\
\text { ees } \\
\text { (full- } \\
\text { time } \\
\text { and } \\
\text { part. } \\
\text { time). } \\
\text { Average } \\
\text { lor } \\
\text { year. }\end{array}$ & $\begin{array}{l}\text { Total } \\
\text { pay } \\
\text { zoll }\end{array}$ \\
\hline ALABAMA & 248 & 9,728 & $\$ 4,223$ & 210 & 2,656 & $\$ 998$ \\
\hline Baldw1n & 8 & 170 & 29 & 7 & 16 & 4 \\
\hline Butler & 3 & 49 & 14 & 3 & 9 & 2 \\
\hline Calhoun & 7 & 223 & 84 & 5 & 64 & 20 \\
\hline Clarke & 5 & 83 & 22 & 5 & 16 & 2 \\
\hline Colbert & 3 & 137 & 50 & 2 & 35 & 15 \\
\hline Corington & 8 & 124 & 34 & 7 & 31 & 8 \\
\hline Dellas & 5 & 247 & 61 & 4 & 45 & 21 \\
\hline De Kalb & 5 & 134 & 14 & 3 & 10 & 3 \\
\hline Escambie & 3 & 99 & 27 & 2 & 23 & 8 \\
\hline
\end{tabular}

Figure 8: An example of the county-level hotel information from the 1935 Census of Business. 


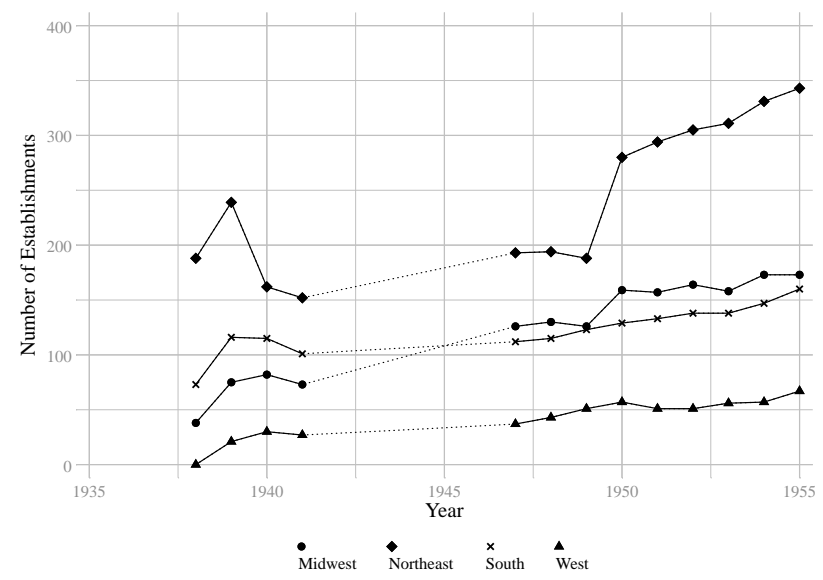

(a) Number of formal accommodations

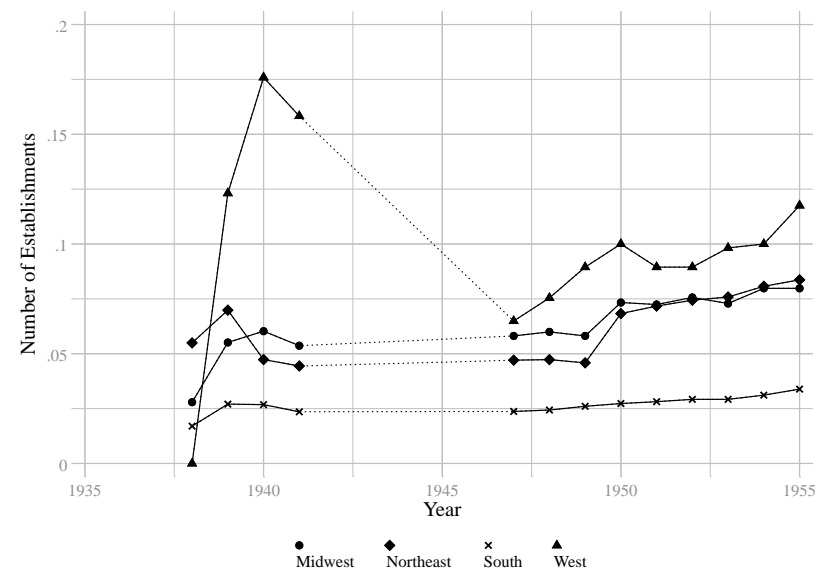

(b) Formal accommodations by black population

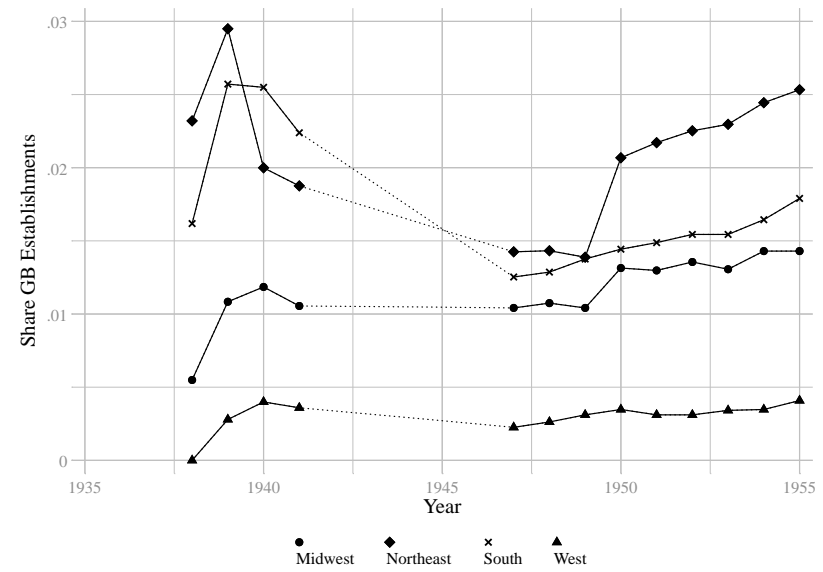

(c) Share of total accommodations that are listed in the Green Books

Figure 9: Total number of formal accommodations, formal accommodations per 1,000 black population, and share of all accommodations that are listed in the Green Books, split by region. 


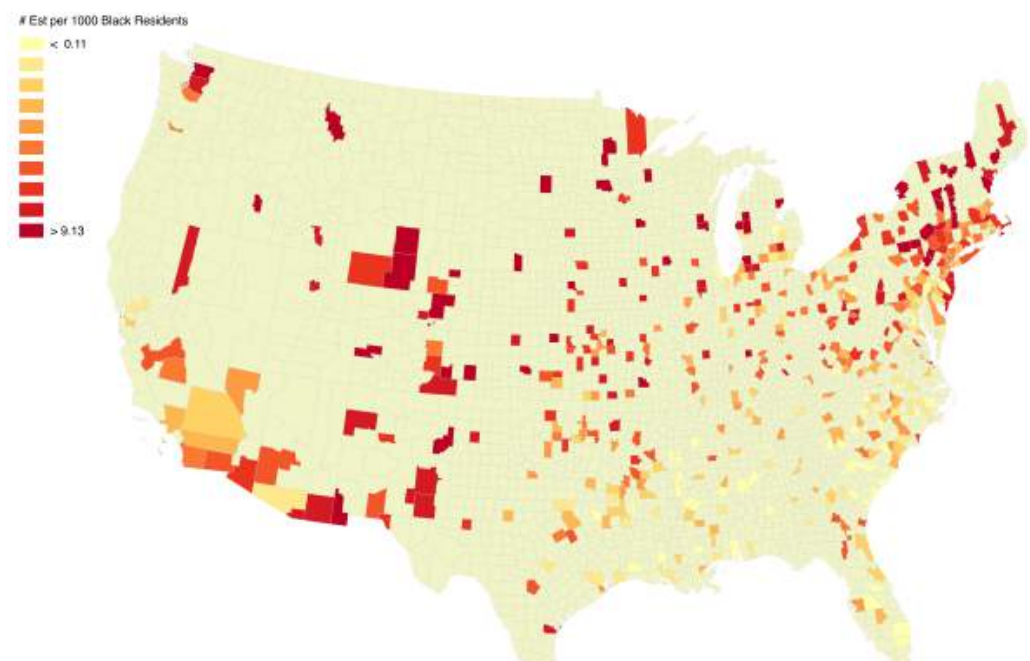

Figure 10: The number of Green Book establishments per 1000 African American residents in 1950 . 


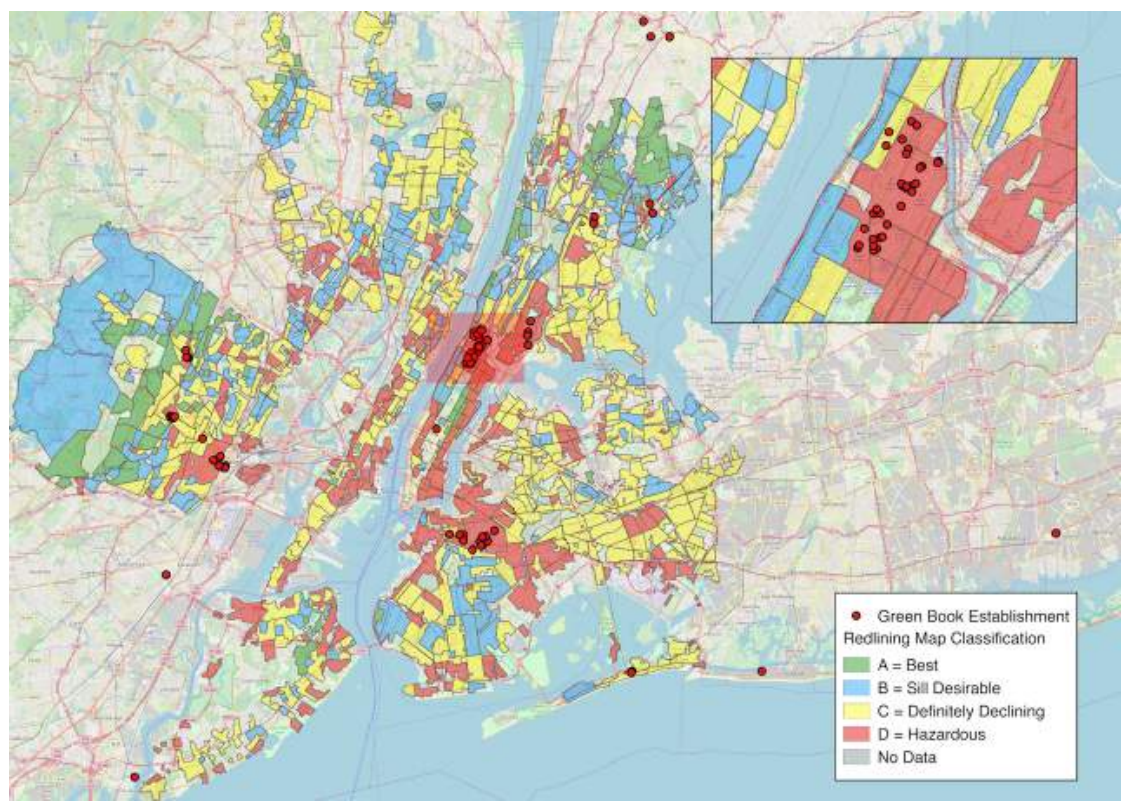

Figure 11: Redlining and the location of Green Book establishments in New York, NY, and Newark, NJ in 1956. 


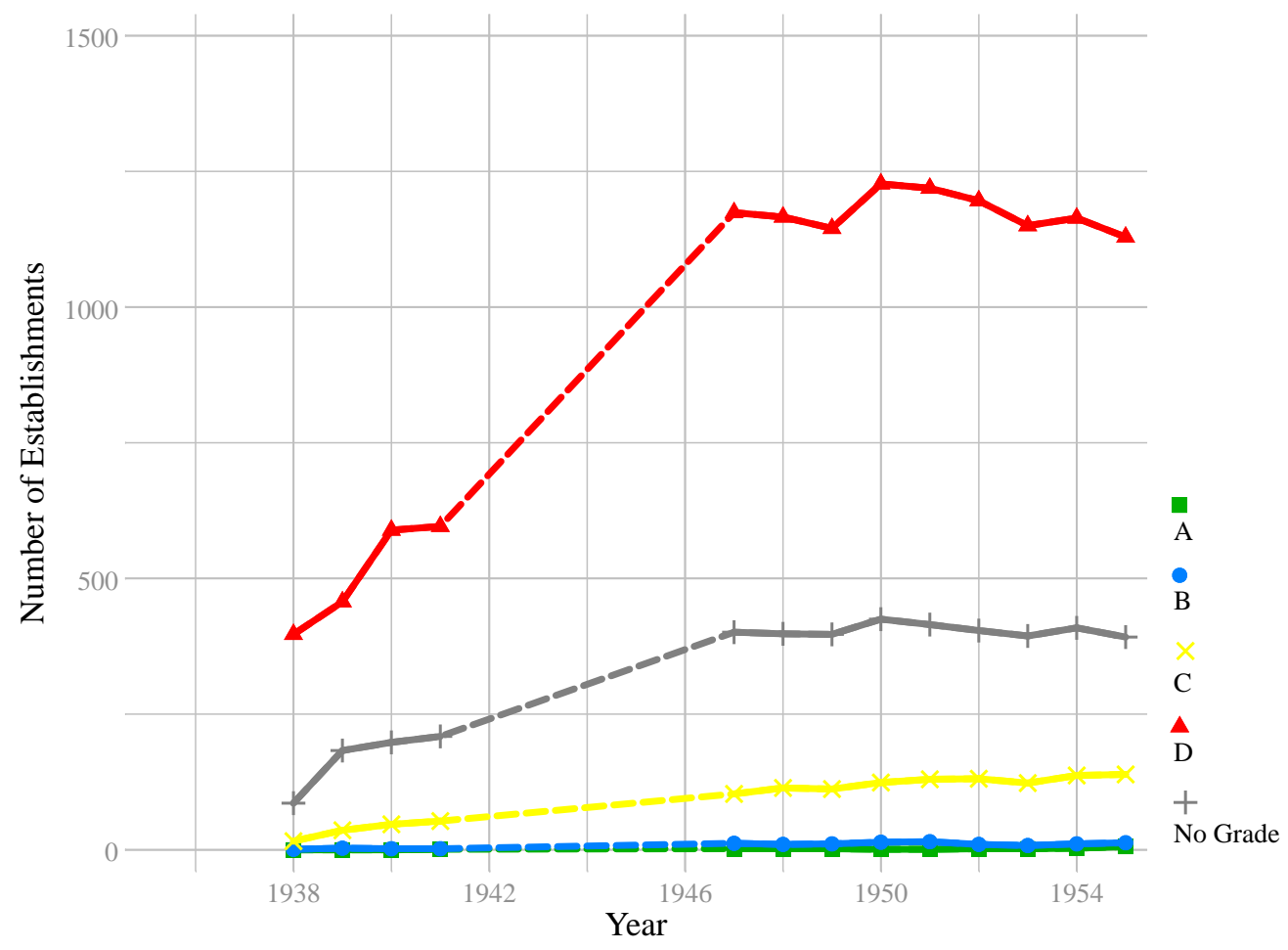

Figure 12: Number of establishments over time by HOLC grade. 


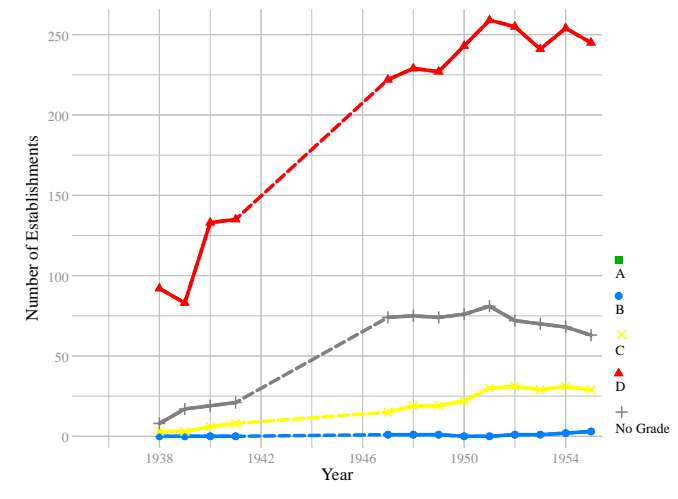

(a) Barber Shops

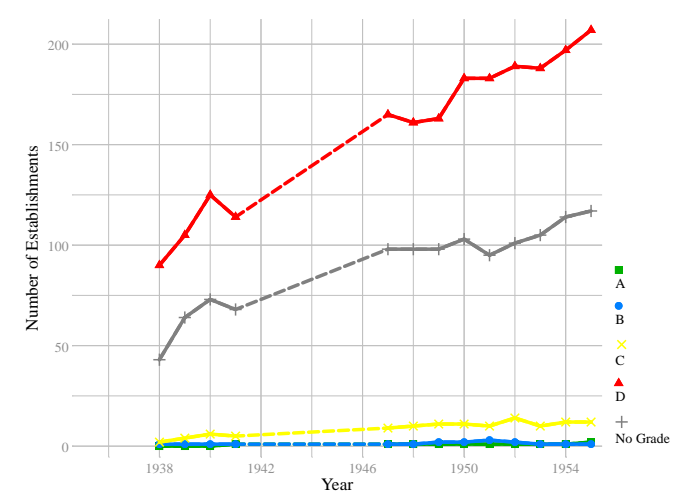

(c) Formal Accommodations

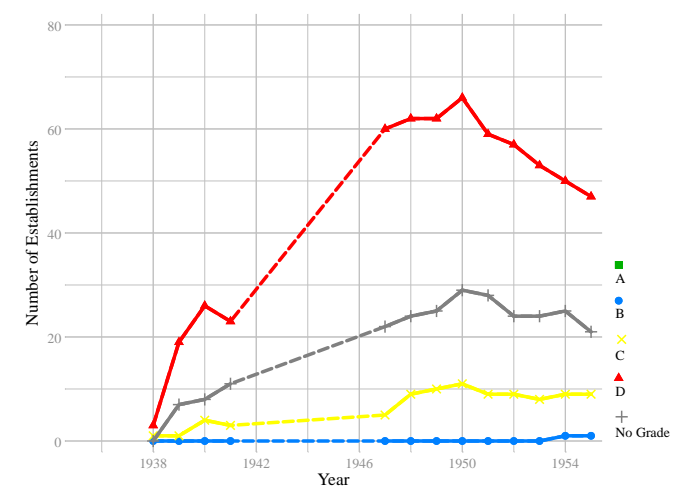

(e) Gasoline

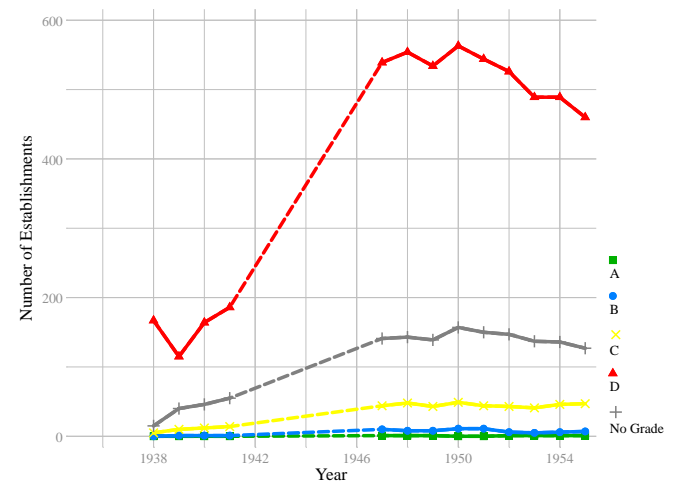

(b) Eating and Drinking

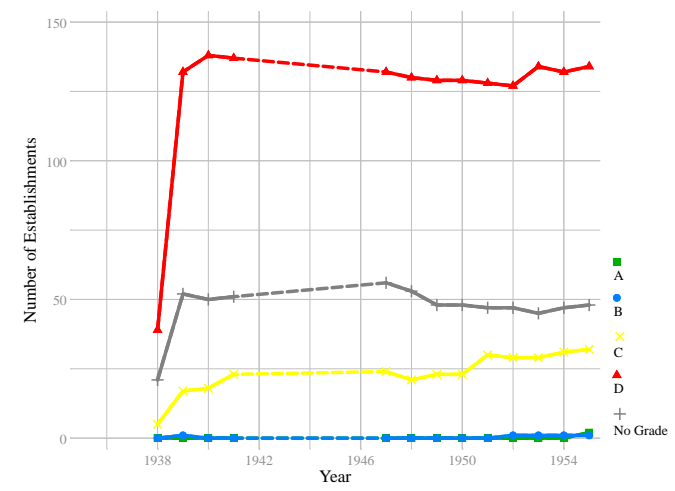

(d) Informal Accommodations

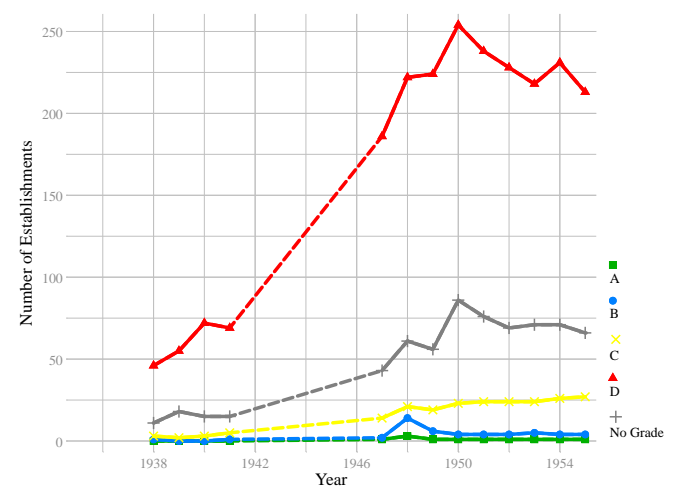

(f) Other

Figure 13: Number of establishments over time by HOLC grade and by industry. 


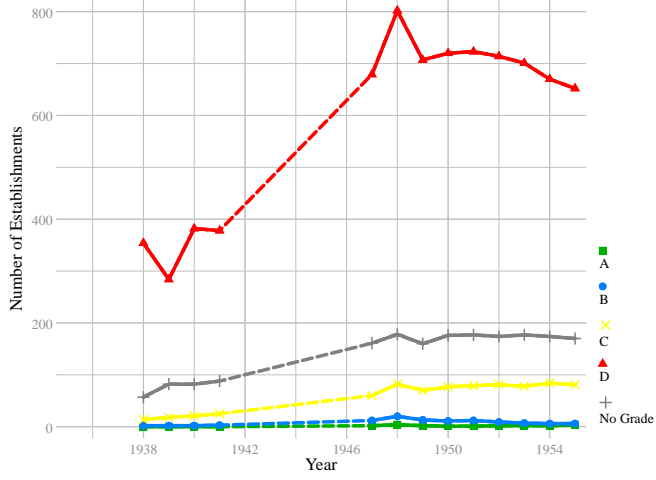

(a) Northeast

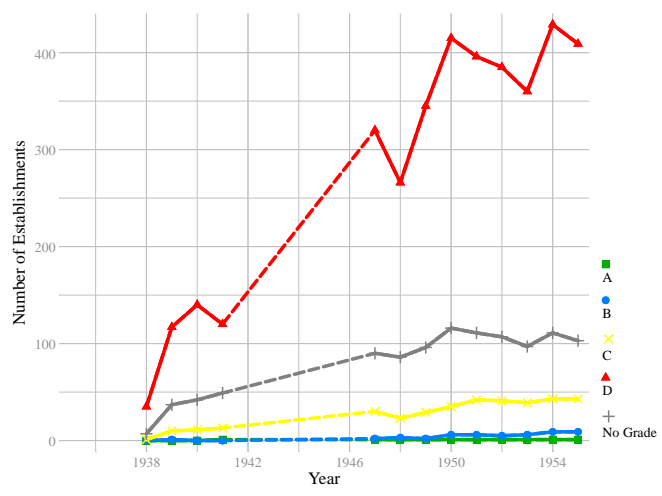

(c) Midwest

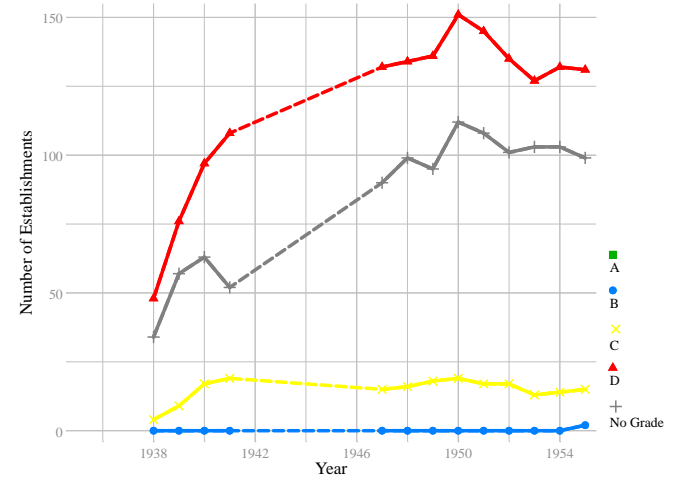

(b) South

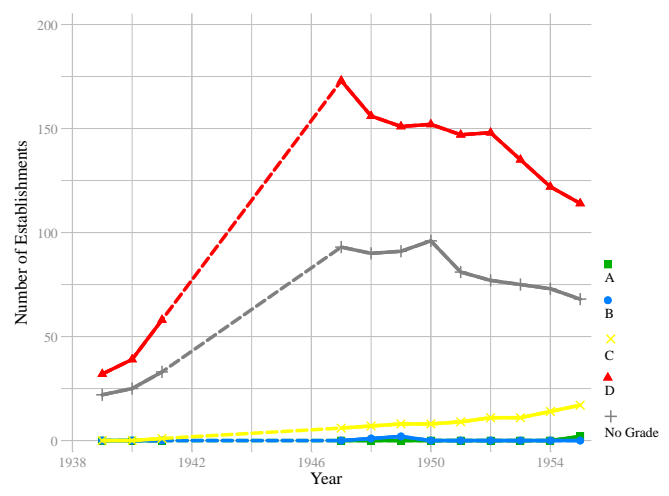

(d) West

Figure 14: Number of establishments over time by HOLC grade and by region. 


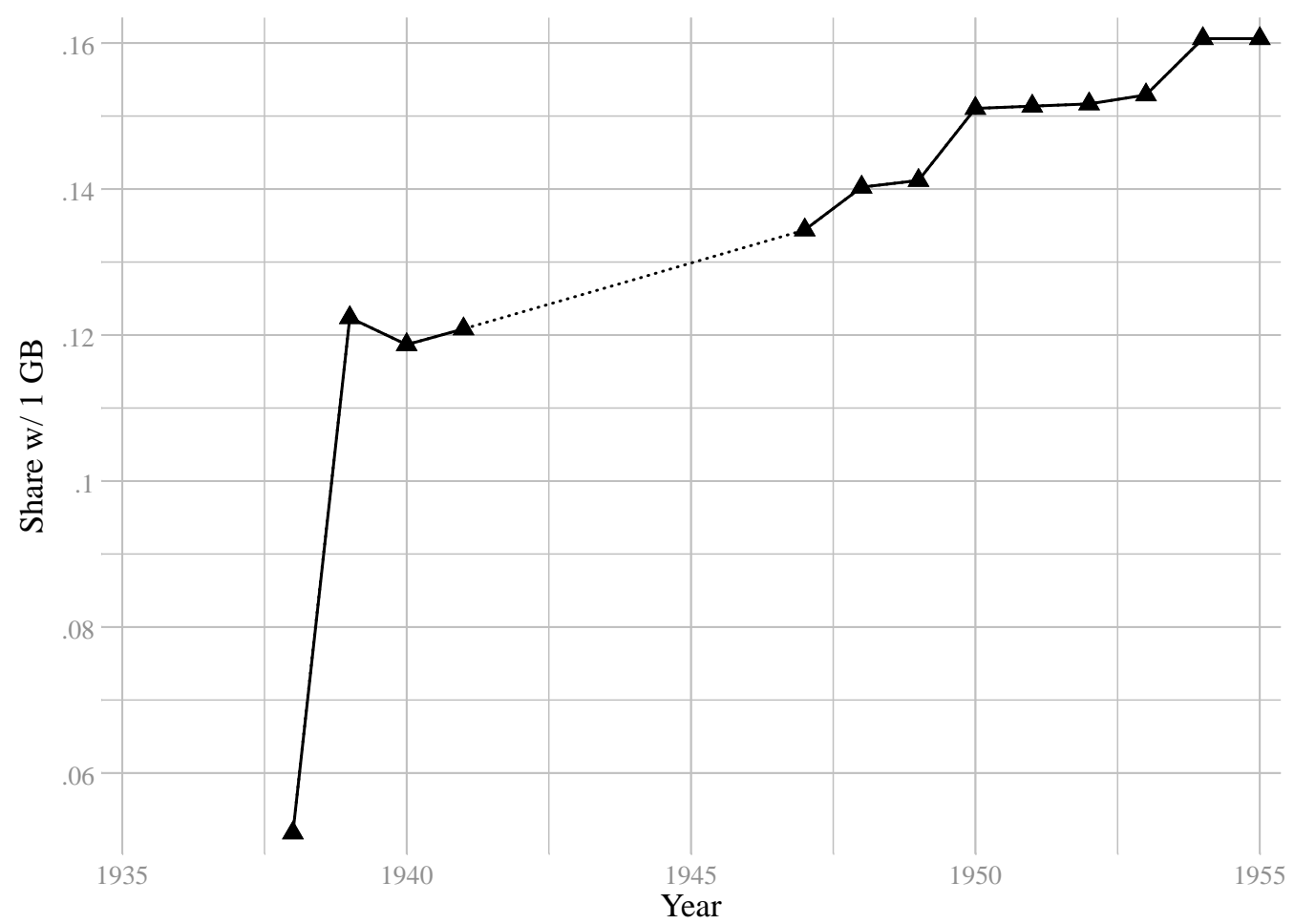

Figure 15: The share of counties with at least one Green Book establishment. 


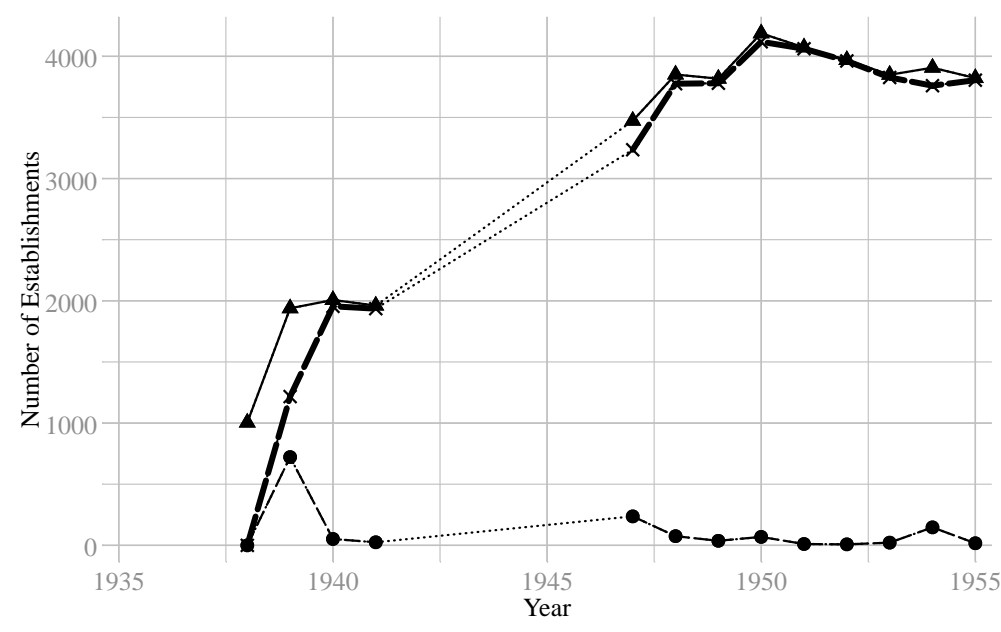

$\Delta$

$\bullet$

$\underset{\text { Total No. of Establishments }}{\bullet}$ No. Est. in New Counties $\stackrel{\times}{\text { N. Est. in Existing Counties }}$

(a) Total number of establishments

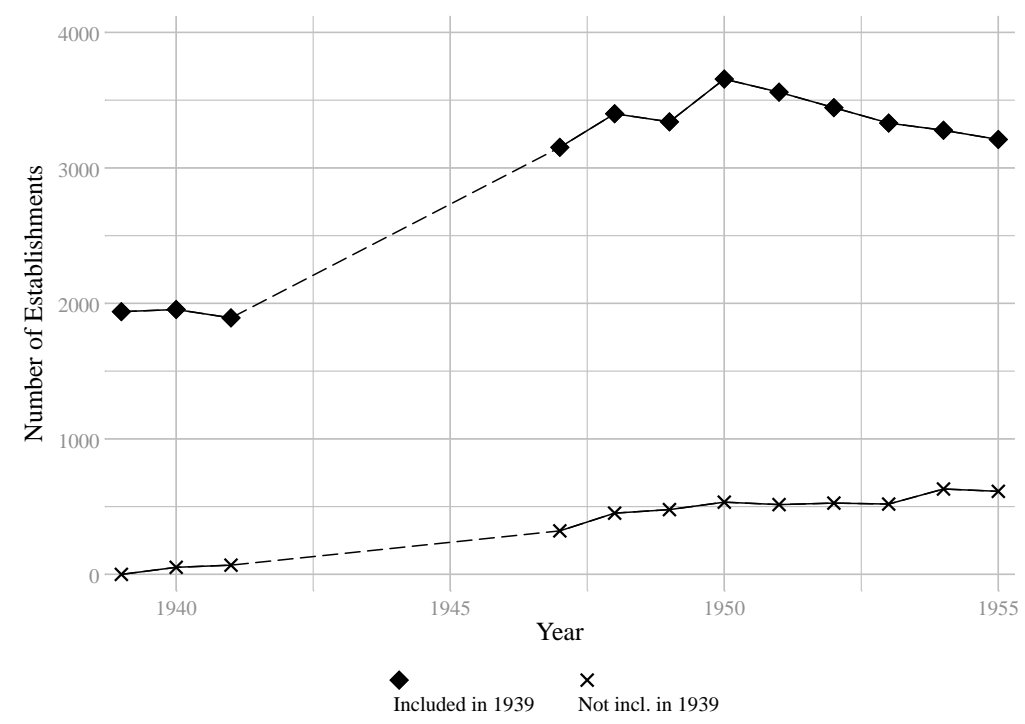

(b) Green Book establishments in "1939 incumbent" and "new entrant" counties

Figure 16: Geographic coverage and Green Book listings growth 


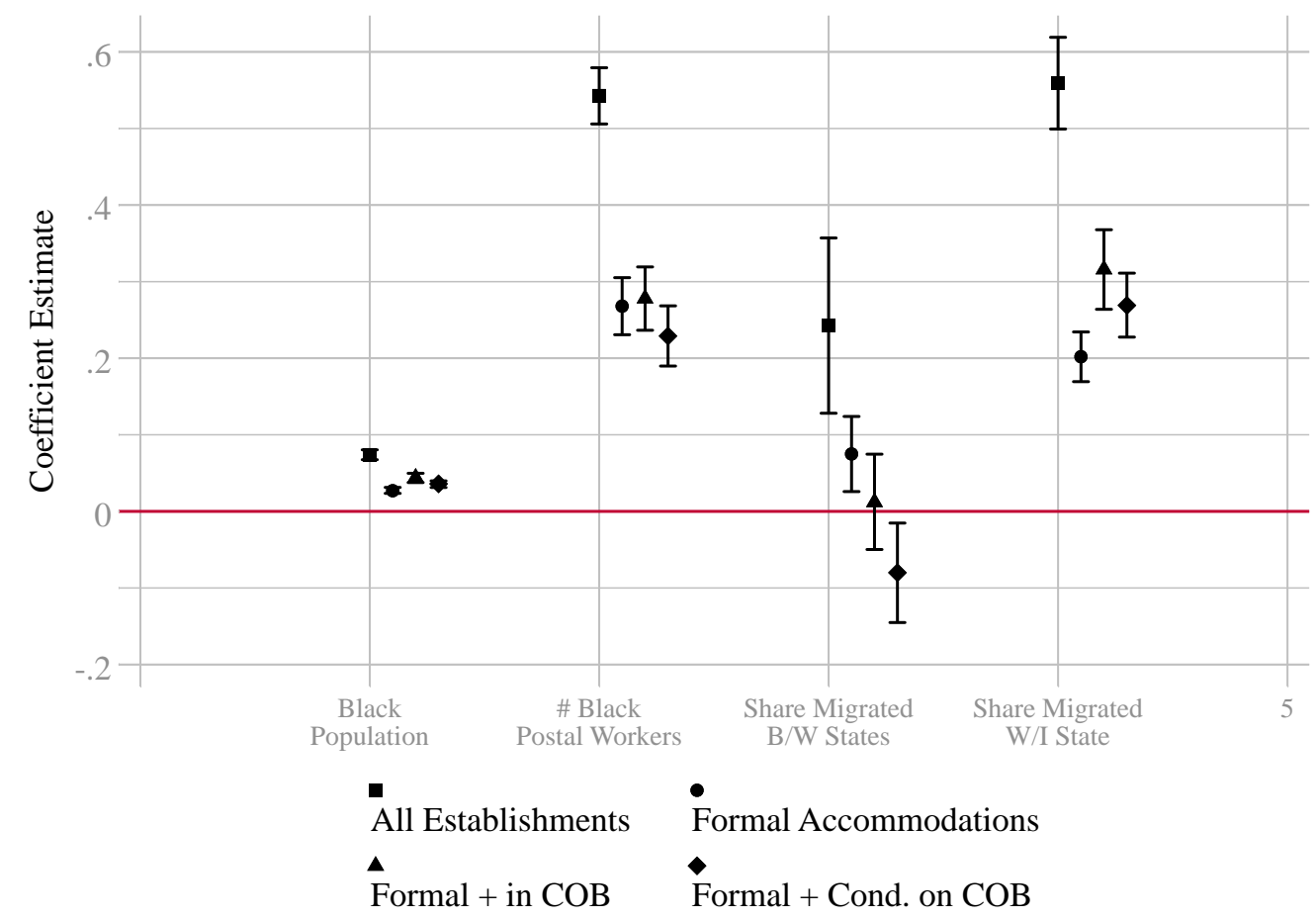

Figure 17: Coefficient estimates and 90\% confidence intervals from separate $\sinh -\sinh$ regressions of the number of Green Book listings on a set of correlates in 1940. Regressions are estimated at the county level and estimates are conditional on the log of the black population (with the exception of the elasticity with respect to the black population). Coefficient estimates marked "All Establishments" regress the total number of Green Book establishments on each measure of discrimination/segregation. "Formal Accommodations" restrict the analysis to formal lodging. "Formal + In COB" restricts the analysis to formal lodging and only includes counties for which we also have data from the 1935 Census of Business (some were omitted due to disclosure rules). "Formal + Cond. on COB" restricts the analysis to formal accommodations in counties for which we have Census of Business data and conditions on the total number of hotels in these counties. 


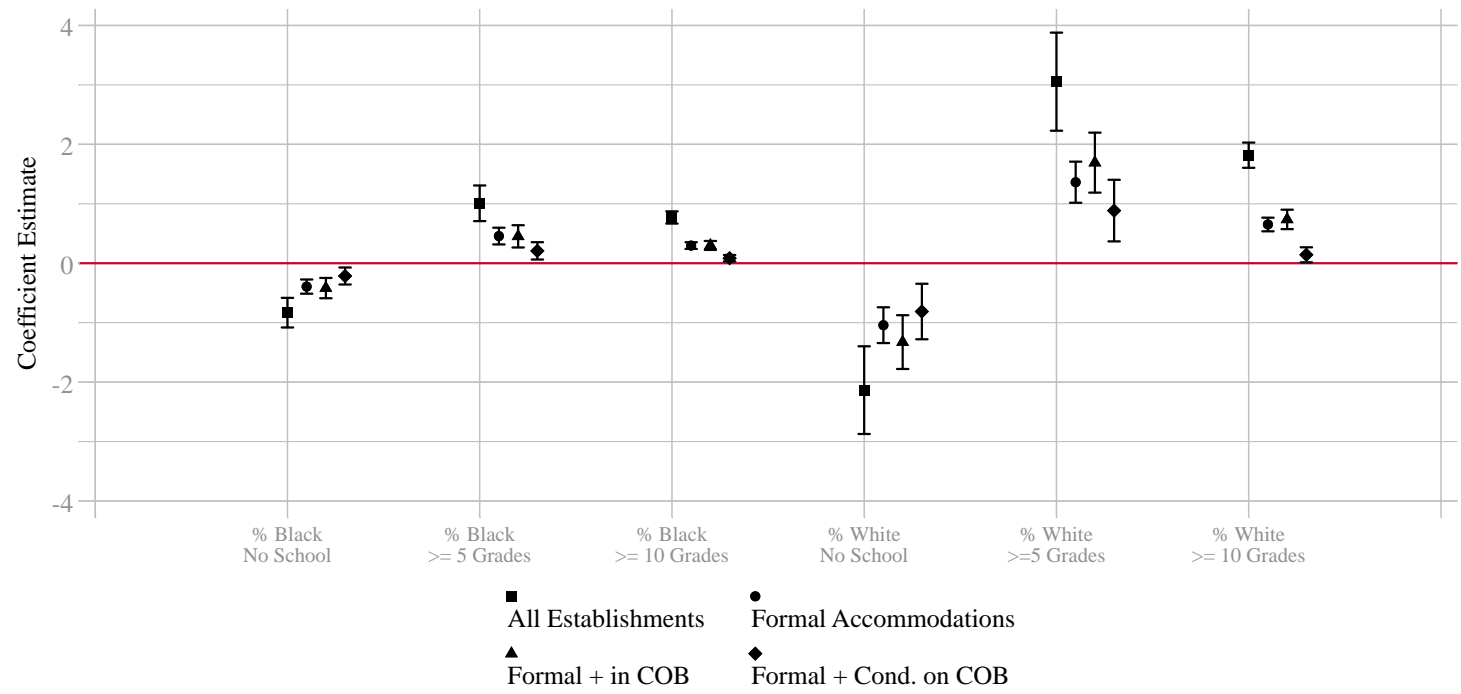

Figure 18: Coefficient estimates and 90\% confidence intervals from separate sinh - sinh regressions of the number of Green Book listings on a set of correlates in 1940. Regressions are estimated at the county level and estimates are conditional on the log of the black population (with the exception of the elasticity with respect to the black population). Coefficient estimates marked "All Establishments" regress the total number of Green Book establishments on each measure of discrimination/segregation. "Formal Accommodations" restrict the analysis to formal lodging. "Formal + In COB" restricts the analysis to formal lodging and only includes counties for which we also have data from the 1935 Census of Business (some were omitted due to disclosure rules). "Formal + Cond. on COB" restricts the analysis to formal accommodations in counties for which we have Census of Business data and conditions on the total number of hotels in these counties. 


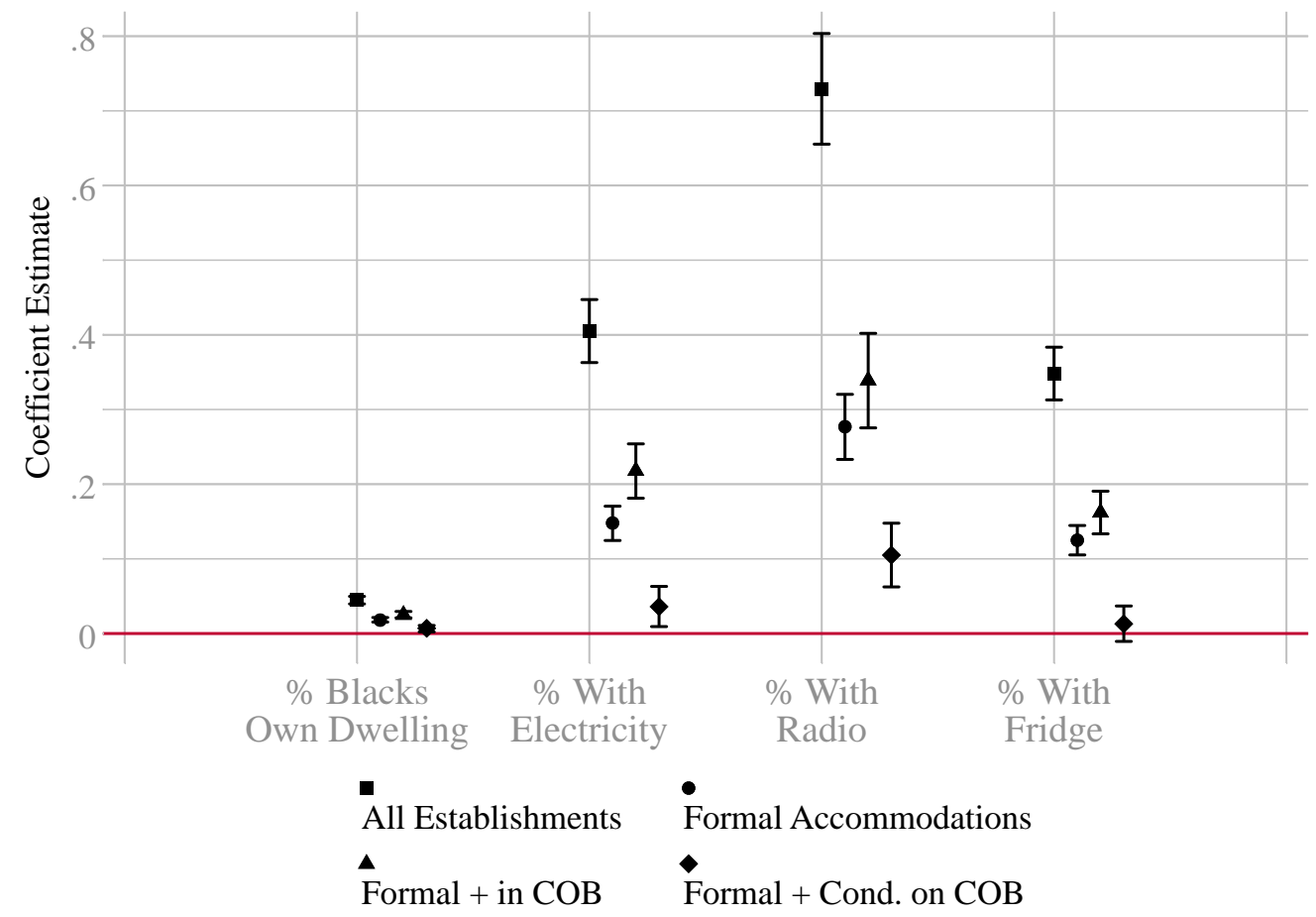

Figure 19: Coefficient estimates and 90\% confidence intervals from separate $\sinh -\sinh$ regressions of the number of GB listings on measures of material wellbeing in 1940. Regressions are estimated at the county level and estimates are conditional on the log of the black population. Coefficient estimates marked "All Establishments" regress the total number of Green Book establishments on each measure of discrimination/segregation. "Formal Accommodations" restrict the analysis to formal lodging. "Formal + In COB" restricts the analysis to formal lodging and only includes counties for which we also have data from the 1935 Census of Business (some were omitted due to disclosure rules). "Formal + Cond. on COB" restricts the analysis to formal accommodations in counties for which we have Census of Business data and conditions on the total number of hotels in these counties. 


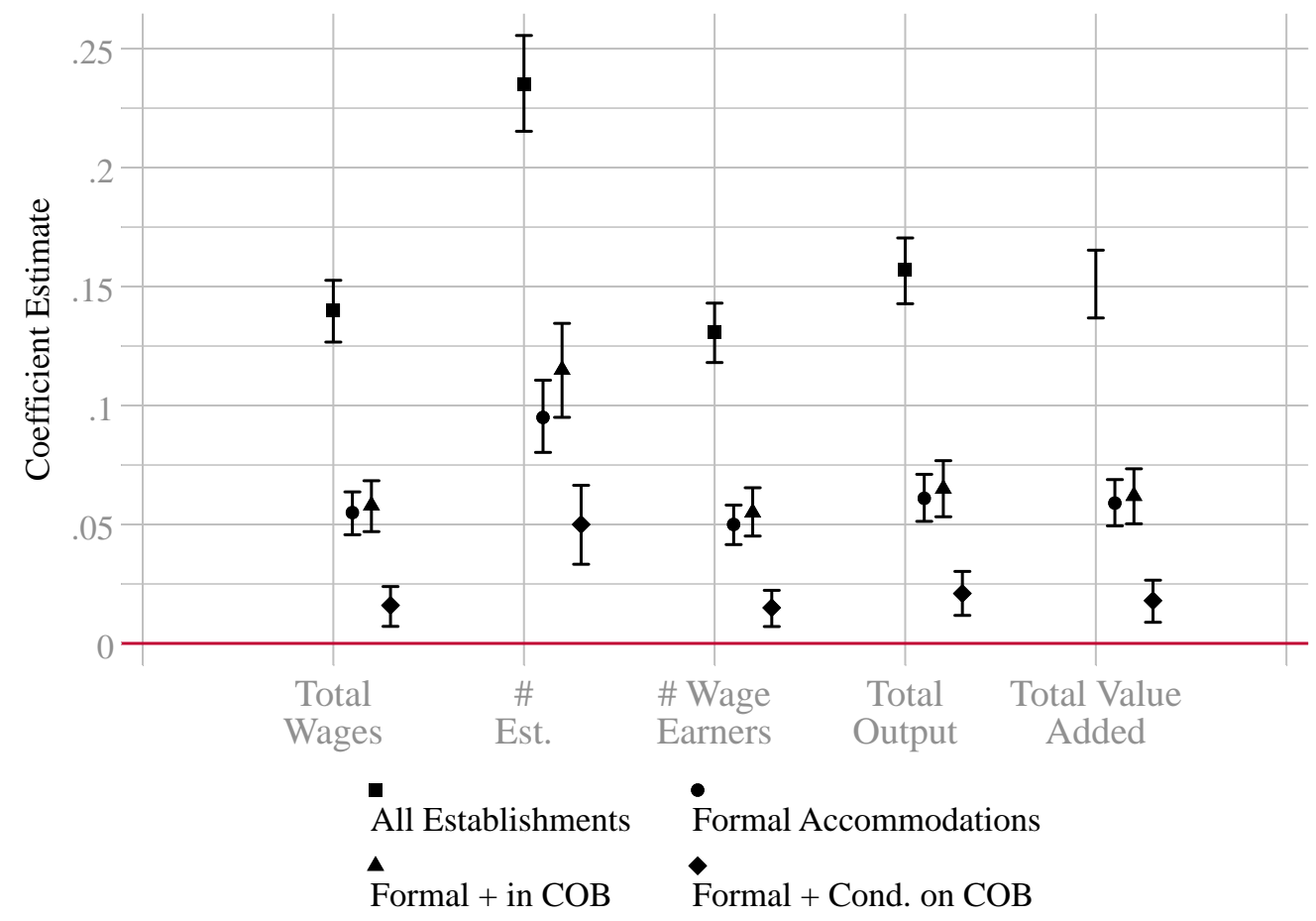

Figure 20: Coefficient estimates and 90\% confidence intervals from separate $\sinh -\sinh$ regressions of the number of GB listings on the prevalence of manufacturing in 1940. Regressions are estimated at the county level and estimates are conditional on the log of the black population. Coefficient estimates marked "All Establishments" regress the total number of Green Book establishments on each measure of discrimination/segregation. "Formal Accommodations" restrict the analysis to formal lodging. "Formal + In COB" restricts the analysis to formal lodging and only includes counties for which we also have data from the 1935 Census of Business (some were omitted due to disclosure rules). "Formal + Cond. on COB" restricts the analysis to formal accommodations in counties for which we have Census of Business data and conditions on the total number of hotels in these counties. 


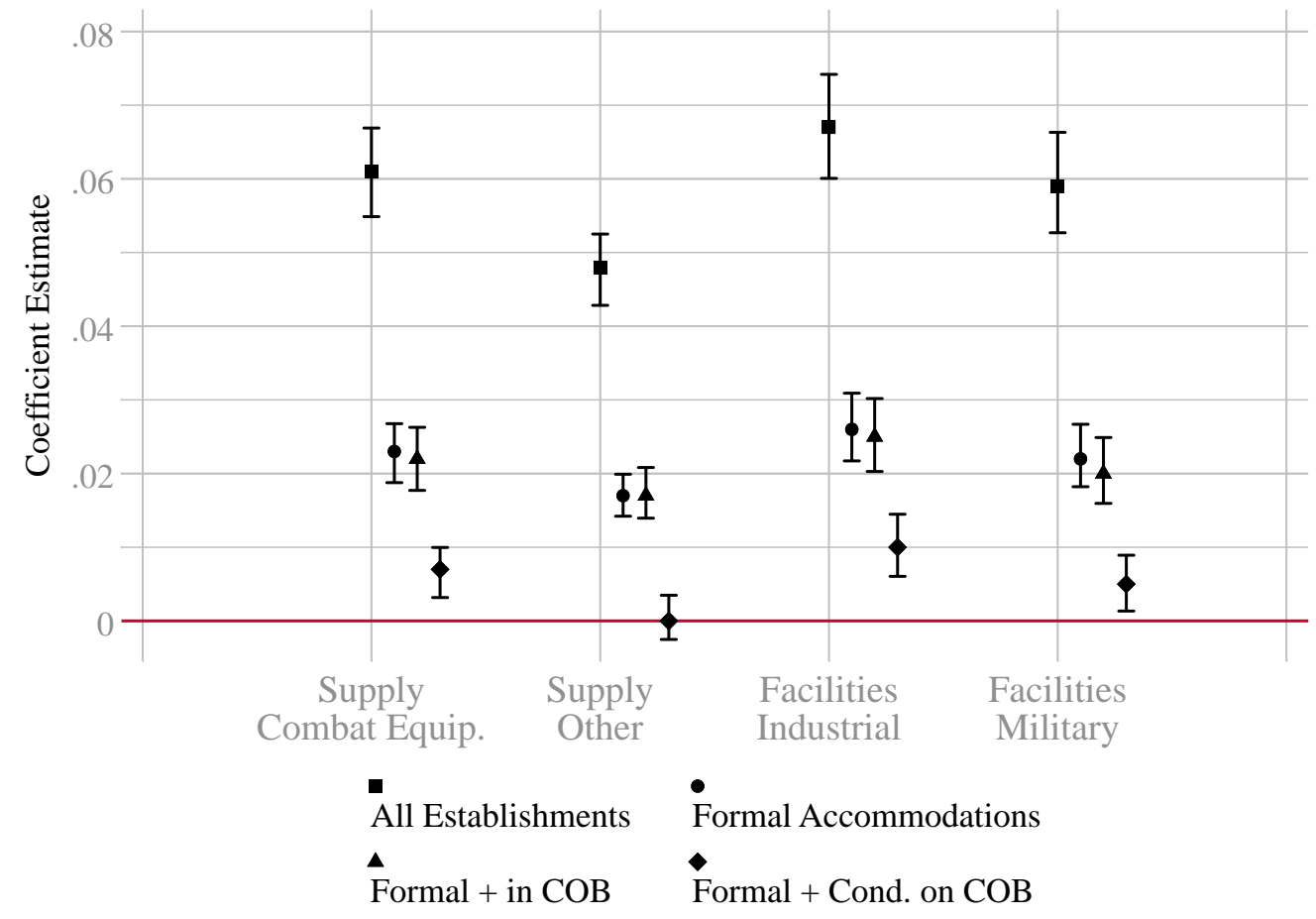

Figure 21: Coefficient estimates and 90\% confidence intervals from separate $\sinh -\sinh$ regressions of the number of GB listings on WWII contracts. Regressions are estimated at the county level and estimates are conditional on the log of the black population. Coefficient estimates marked "All Establishments" regress the total number of Green Book establishments on each measure of discrimination/segregation. "Formal Accommodations" restrict the analysis to formal lodging. "Formal + In COB" restricts the analysis to formal lodging and only includes counties for which we also have data from the 1935 Census of Business (some were omitted due to disclosure rules). "Formal + Cond. on COB" restricts the analysis to formal accommodations in counties for which we have Census of Business data and conditions on the total number of hotels in these counties. 


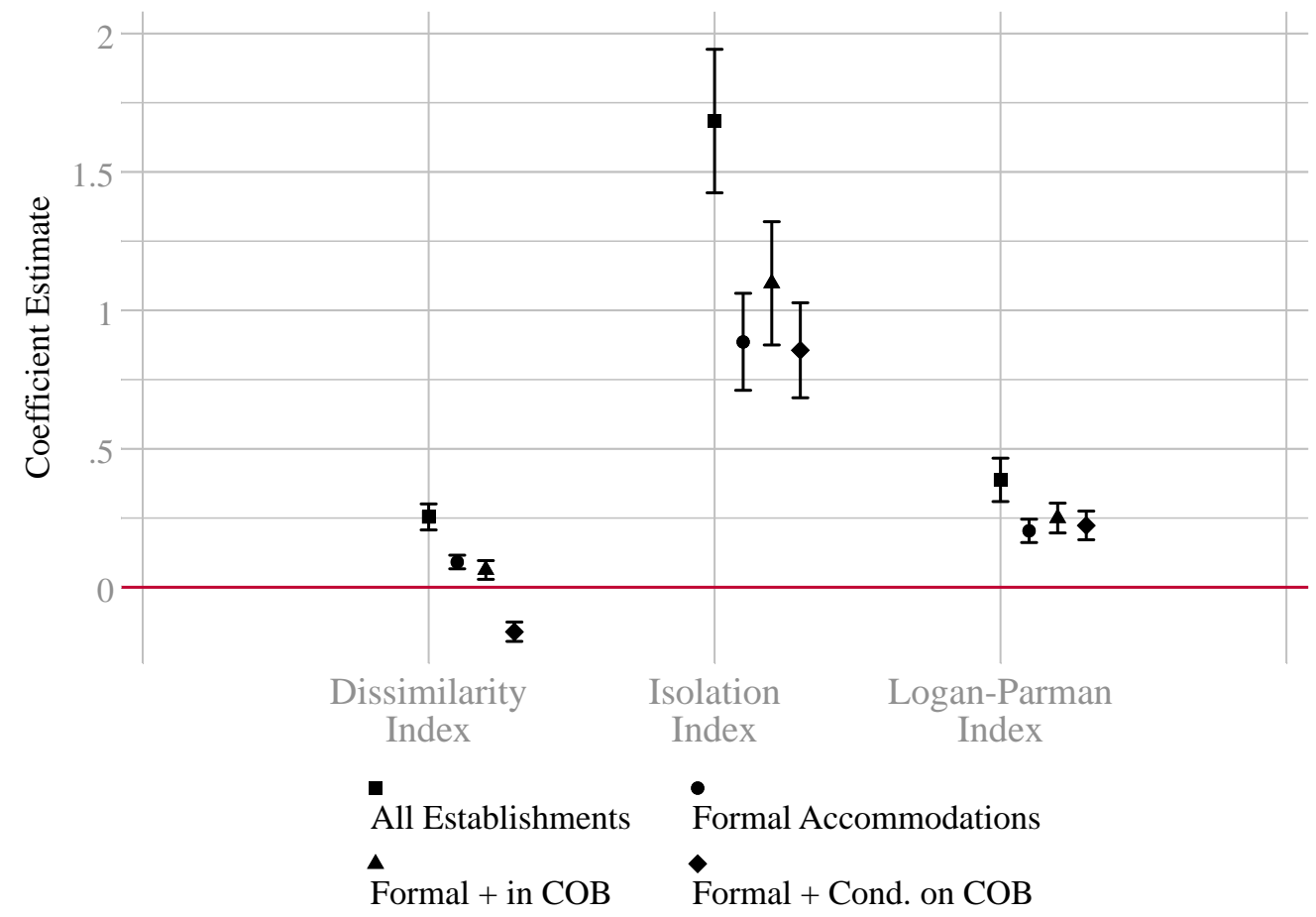

Figure 22: Coefficient estimates and 90\% confidence intervals from separate $\sinh -\sinh$ regressions of the number of GB listings on measures of segregation in 1940. Regressions are estimated at the county level and estimates are conditional on the log of the black population. Coefficient estimates marked "All Establishments" regress the total number of Green Book establishments on each measure of discrimination/segregation. "Formal Accommodations" restrict the analysis to formal lodging. "Formal + In COB" restricts the analysis to formal lodging and only includes counties for which we also have data from the 1935 Census of Business (some were omitted due to disclosure rules). "Formal + Cond. on COB" restricts the analysis to formal accommodations in counties for which we have Census of Business data and conditions on the total number of hotels in these counties. 


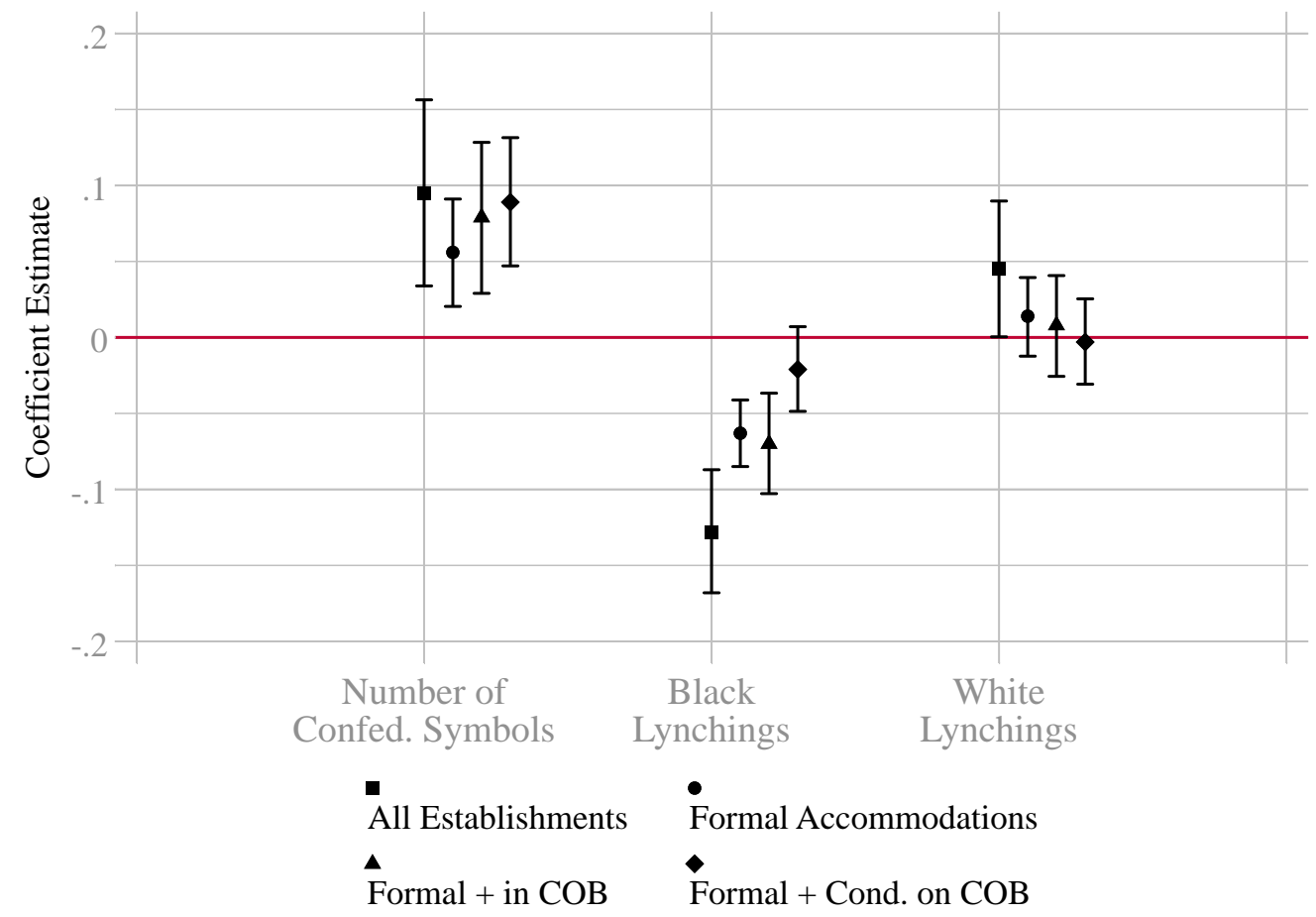

Figure 23: Coefficient estimates and 90\% confidence intervals from separate $\sinh -\sinh$ regressions of the number of GB listings on measures of discrimination in 1940. Regressions are estimated at the county level and estimates are conditional on the log of the black population. Coefficient estimates marked "All Establishments" regress the total number of Green Book establishments on each measure of discrimination/segregation. "Formal Accommodations" restrict the analysis to formal lodging. "Formal + In COB" restricts the analysis to formal lodging and only includes counties for which we also have data from the 1935 Census of Business (some were omitted due to disclosure rules). "Formal + Cond. on COB" restricts the analysis to formal accommodations in counties for which we have Census of Business data and conditions on the total number of hotels in these counties. 


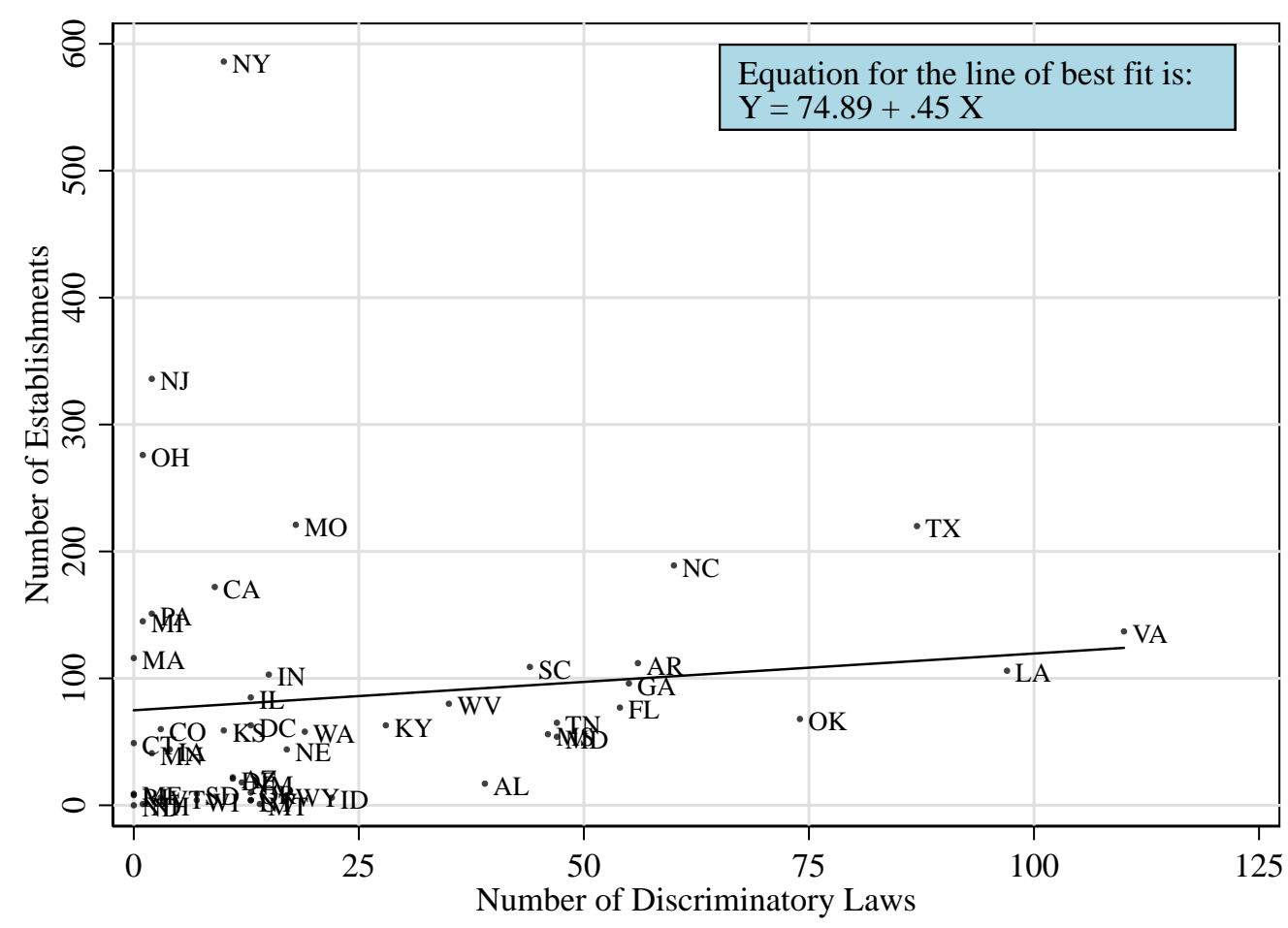

Figure 24: This figure displays state-level counts of the number of laws related to discriminatory practices on the horizontal axis and state-level counts of the number of Green Book establishments on the vertical axis. These counts are measured as of 1950. Counts of discrimination laws were collected by the authors from compiling the work of Murray (1950). 


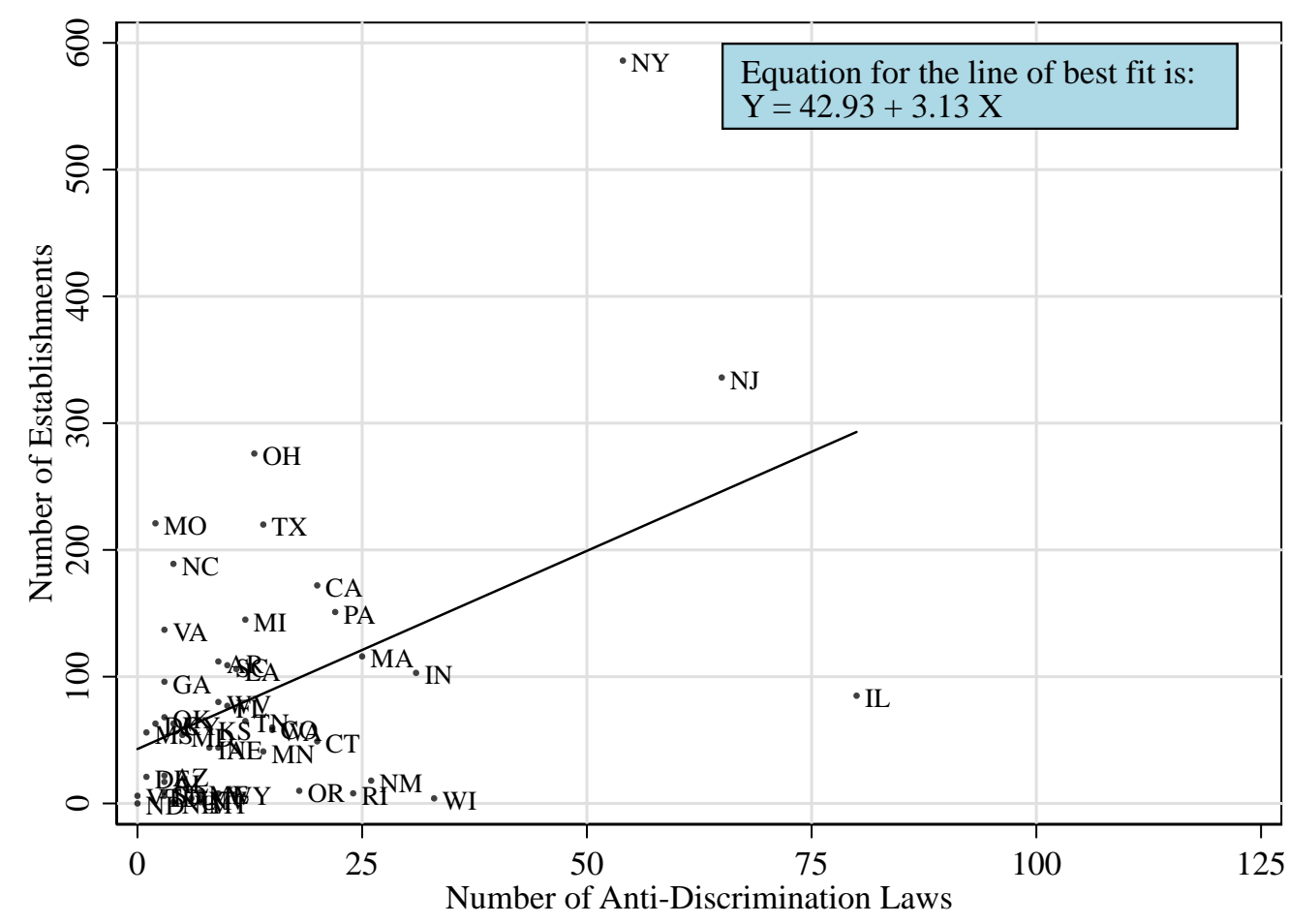

Figure 25: This figure displays state-level counts of the number of laws related to antidiscrimination on the horizontal axis and state-level counts of the number of Green Book establishments on the vertical axis. These counts are measured as of 1950. Counts of discrimination laws were collected by the authors from compiling the work of Murray (1950). 


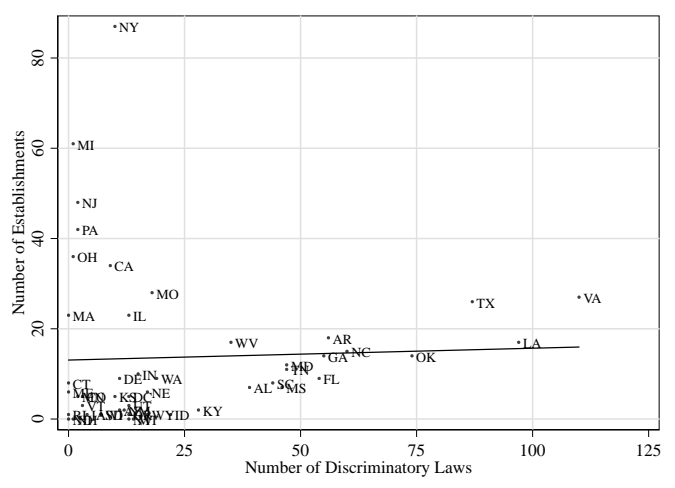

(a) Formal Accommodations

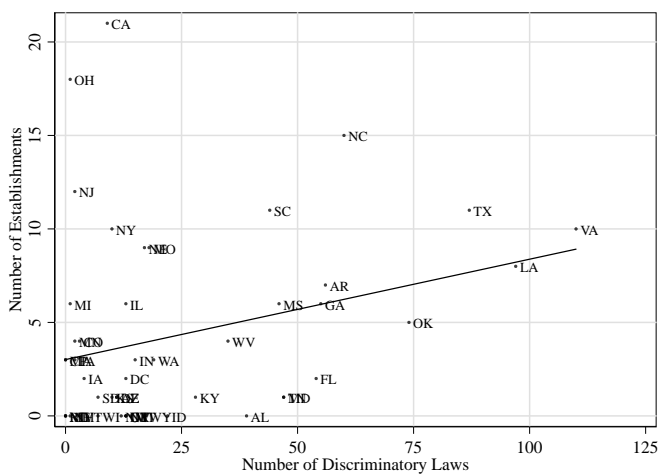

(c) Service Stations

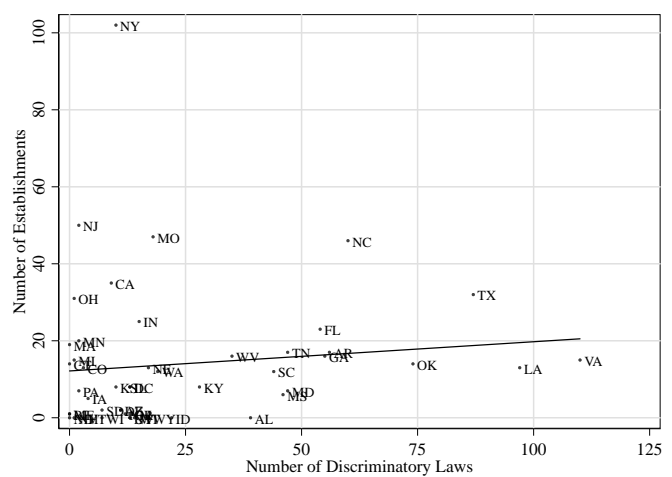

(e) Other

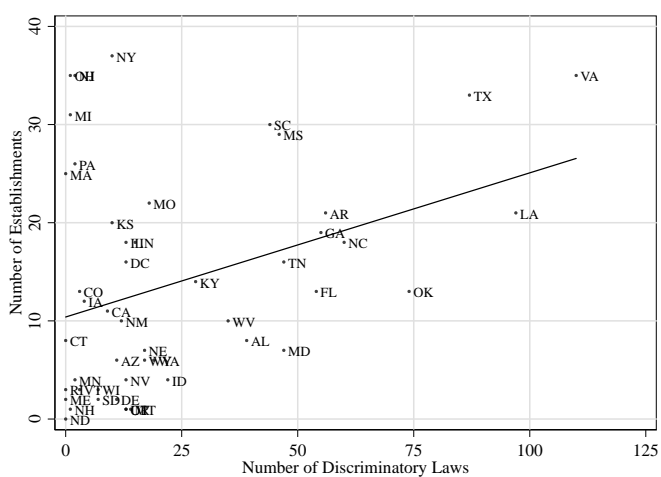

(b) Informal Accommodations

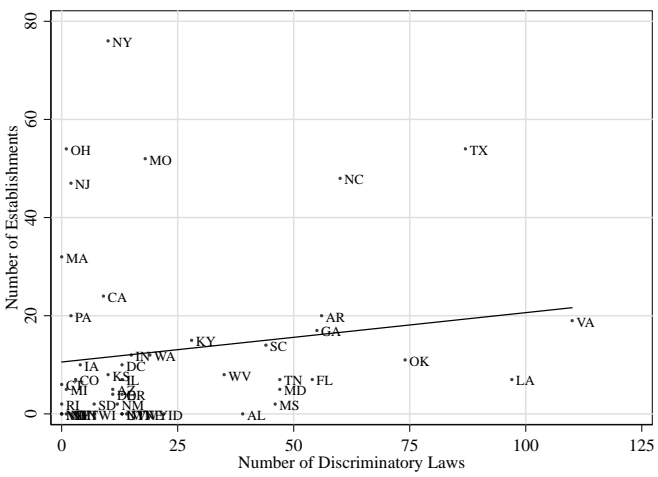

(d) Beauty and barber shops

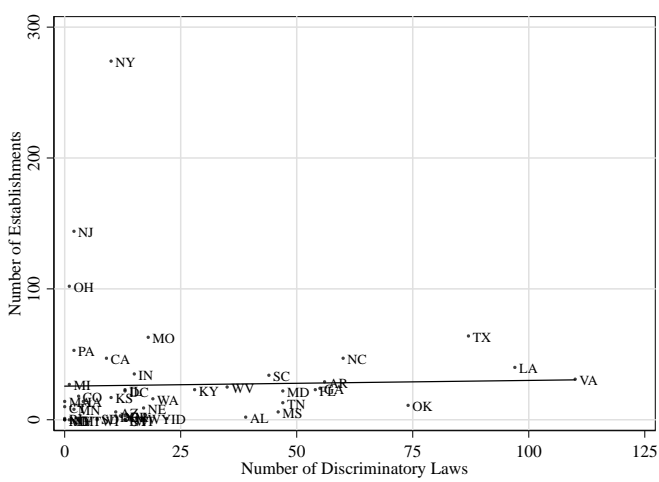

(f) Eating and dining

Figure 26: This figure displays state-level counts of the number of laws related to discrimination on the horizontal axis and state-level counts of the number of Green Book establishments on the vertical axis. These counts are measured as of 1950 and plots are shown for each category of industry. Counts of discrimination laws were collected by the authors from compiling the work of Murray (1950). 


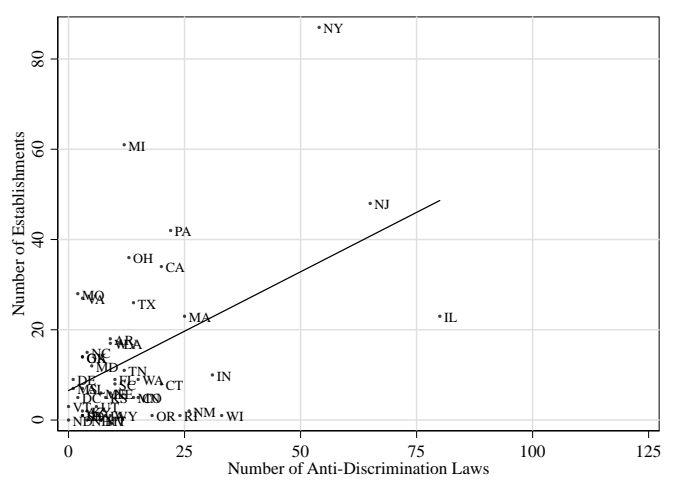

(a) Formal Accommodations

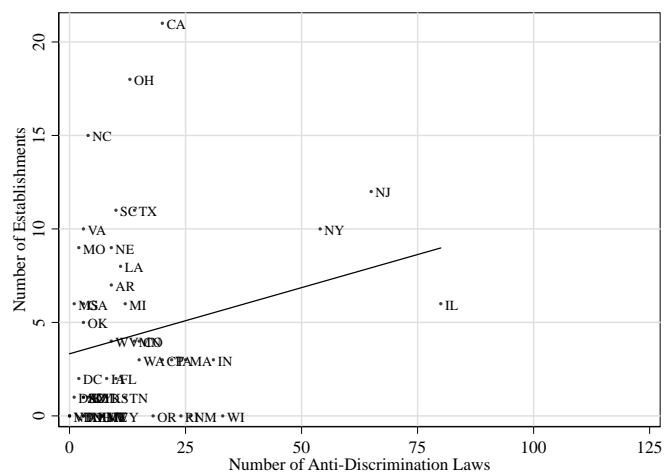

(c) Service Stations

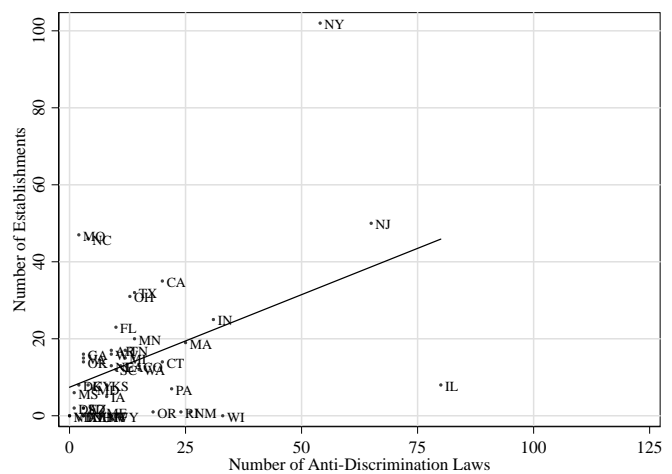

(e) Other

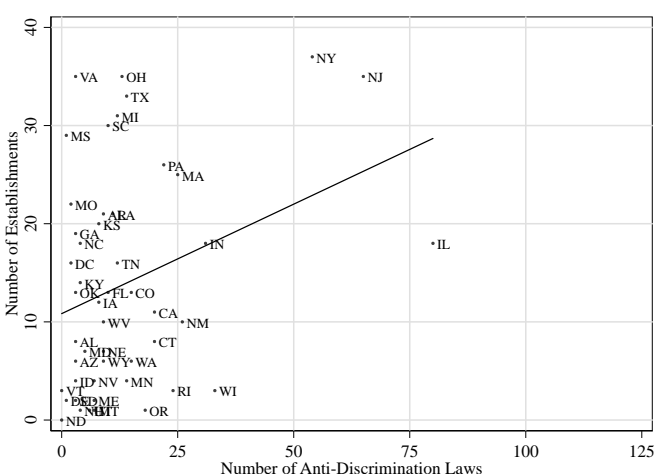

(b) Informal Accommodations

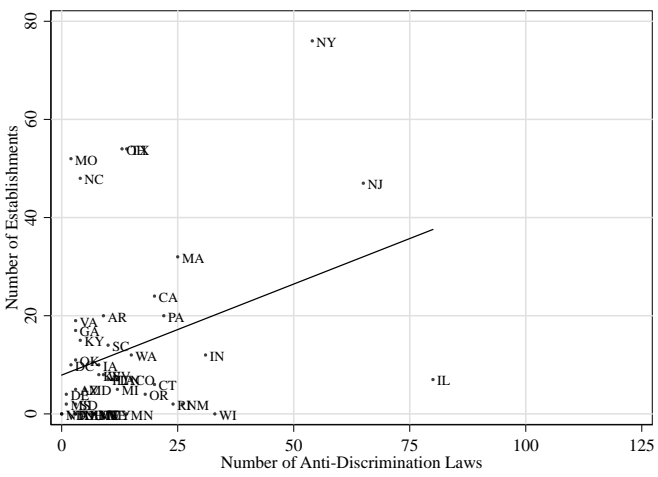

(d) Beauty and barber shops

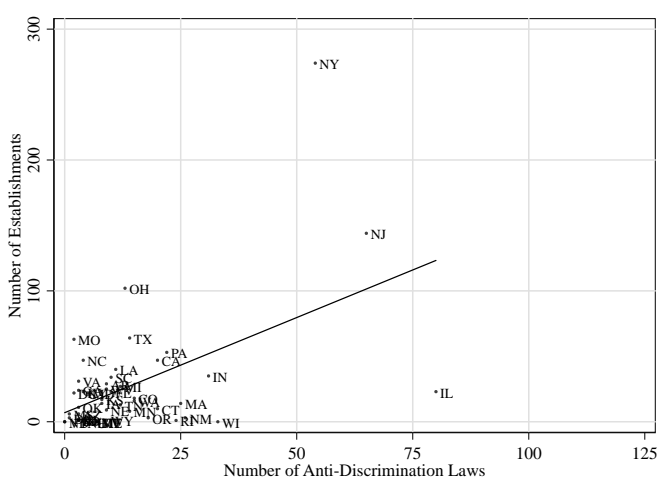

(f) Eating and dining

Figure 27: This figure displays state-level counts of the number of laws related to antidiscrimination on the horizontal axis and state-level counts of the number of Green Book establishments on the vertical axis. These counts are measured as of 1950 and plots are shown for each category of industry. Counts of discrimination laws were collected by the authors from compiling the work of Murray (1950). 